Portland State University

PDXScholar

1978

\title{
A Comparative Study of Persons Completing and Not Completing an Alcoholism Treatment Clinic's Group Intake Process
}

Timothy W. Hallinan

Portland State University

Eric J. Huelshoff

Portland State University

Follow this and additional works at: https://pdxscholar.library.pdx.edu/open_access_etds

Part of the Counseling Commons, and the Social Work Commons Let us know how access to this document benefits you.

\section{Recommended Citation}

Hallinan, Timothy W. and Huelshoff, Eric J., "A Comparative Study of Persons Completing and Not Completing an Alcoholism Treatment Clinic's Group Intake Process" (1978). Dissertations and Theses. Paper 2743.

https://doi.org/10.15760/etd.2737

This Thesis is brought to you for free and open access. It has been accepted for inclusion in Dissertations and Theses by an authorized administrator of PDXScholar. Please contact us if we can make this document more accessible: pdxscholar@pdx.edu. 


\title{
A COMPARATIVE STUDY OF PERSONS COMPLETING AND
}

NOT COMPLETING AN ALCOHOLISM TREATMENT

\section{CLINIC'S GROUP' INTAKE' PROCESS}

\author{
by \\ TIMOTHY W. HALLINAN \\ and \\ ERIC J. HUELSHOFF
}

A practicum submitted in partial fulfillment of the requirements for the degree of

MASTER OF SOCIAL WORK

Portland State University

1978 


\section{PREFACE}

A major problem of concern to mental health workers is the failure of many clients to begin treatment after completing an intake interview, or to terminate treatment prematurely. A number of studies have been made comparing pretreatment dropouts with clients entering treatment, and treatment dropouts with clients remaining in treatment, on different personality, demographic, and social-historical variables. The intent of these studies was to determine the characteristics of dropouts, with hopes of using this information predictively to determine which clients would most likely not begin treatment or would drop out of treatment prematurely.

The present study is concerned with pre-treatment dropouts in an outpatient alcoholism treatment clinic. Previous pre-treatment dropout studies have been made in settings where there is one intake session followed by a treatment program. In the setting of the present study, however, there is an extended intake process, consisting of three (and occasionally four) group intake sessions followed by a session of staffing and then treatment. This study, therefore, differs from previous investigations, in that it considers as "pre-treatment dropouts;" those clients who drop 
out at any point during the intake process, " rather than just those clients who do not appear for treatment following an intake session.

For purposes of orientation, we begin with a discussion of the problem of alcoholism and the process of intake.

* The intake process is here considered as beginning at the first session of group intake and ending at the start of the first session of treatment. 


\section{ACKNOWLEDGMENTS}

We would like to indicate here our sincere appreciation to the staff of the Alcohol Treatment and Training Center, especially G. Joseph Colistro, A.C.S.W., Jack Keener, M.A., and Edward M. Scott, Ph.D., for permitting us the use of the facilities in which this study was conducted, as well as for their helpful suggestions.

We are also grateful to Jack Finley, A.C.S.W. for his helpful advice on the practicum, and Nancy Koroloff, M.S.W. for her help with the statistical analysis.

Lastly, we would like to thank the women in our lives, Cynthia Bilbrey and Michele Belott, whose loving support and encouragement was invaluable, and it is to them we dedicate this work. 
TABLE OF CONTENTS

PAGE

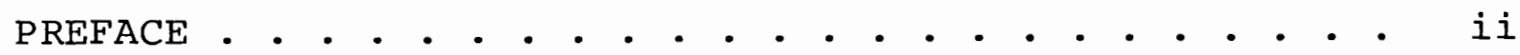

ACKNOWLEDGMENTS . . . . . . . . . . . . . . . iv

LIST OF TABLES . . . . . . . . . . . . . . . . vi vi

CHAPTER

I INTRODUCTION: THE PROBLEM OF ALCOHOLISM • . 1

II INTAKE . . . . . . . . . . . . . 6

III PURPOSE OF STUDY . . . . . . . . . . . . 11

IV REVIEW OF LITERATURE: PRE-TREATMENT AND TREATMENT DROPOUT STUDIES . . . . . . . . 12

$\mathrm{V}$ INSTRUMENTS USED IN STUDY: THE EDWARDS

PERSONAL PREFERENCE SCHEDULE AND THE

SCHEDULE OF RECENT EXPERIENCE . . . . . . 21

VI THE ALCOHOL TREATMENT AND TRAINING CENTER • • 25

VII THE CENTER POPULATION . . . . . . . . . 30

VIII METHODOLOGY . . . . . . . . . . 34

IX RESULTS . . . . . . . . . . . . . . 39

X DISCUSSION OF RESULTS . . . . . . . . . 48

XI CONCLUSION: RECOMMENDATIONS FOR REDUCING

ATTRITION . . . . . . . . . . . . 58

SOURCES CONSULTED . . . . . . . . . . . . 61 


\section{LIST OF TABLES}

TABLE

PAGE

I The Schedule of Recent Experience . . . . 24

II Summary of Findings For Control and

Experimental Groups . . . . . . . 41

II Characteristics of Noncompleters:

Comparison of Present study with

Previous Related Studies . . . . . 49 


\section{CHAPTER I}

INTRODUCTION: THE PROBLEM OF ALCOHOLISM

The potent poison quite o'ercrows my spirit. Hamlet V i

Man has produced and consumed alcoholic beverages for at least 10,000 years. Numerous cults and religious movements have worshiped alcohol as a divine gift, from the earliest Mesopotamian cultures through the Greek and Roman empires and beyond. "The word "alcohol" is derived from the Arabic "al kohl" which referred to a fine black powder used to stain the eyelids. This word later was generalized to mean any liquid "extracted or distilled -- that is, the spirit of some substance, the most common of which was wine, the spirit of the grape" (Scott, 1970, p. 4). Today we no longer see alcohol as a magical substance -- a gift from the gods. Rather, alcohol is seen as a drug neither good nor bad in and of itself, but good or bad in terms of how it is used and in terms of its effect upon individuals and society.

Certainly there is no disagreement about the seriousness of the problem of alcohol abuse and alcoholism in the United States. However, it is difficult to estimate the number of persons with significant alcohol problems in this 
country, as this figure to a large extent depends upon the definition of alcoholism employed. It is the authors' belief that the major criterion should be a significant level of social, psychological, and interpersonal problems secondary to alcohol use. Given this definition it is estimated that ten million United States citizens have alcohol-related problems (Keller, 1974, p. 1).

The level of alcohol consumption in this country has decreased greatly since statistics were first compiled. In 1800 the per capita consumption level for all types of alcoholic beverages by the drinking age population (fifteen years of age and older), was 6.6 gallons of absolute alcohol* per annum, compared to 2.5 gallons in 1970 (Rorabaugh, 1976, p. 361). Between 1790 and 1830 the price of whiskey fell to $25 \dot{c}$ per gallon, which was less than wine, beer, coffee, tea, and milk. At the same time, "Americans retained a belief that liquor was healthful, nutritious, stimulating, and relaxing" (Ibid., p. 361). Recently the level of alcohol consumption in this country has begun to increase. A $32 \%$ overall increase was found between 1958 and 1971 (Keller, 1974, p. 6).

When annual consumption is examined regionally, the Pacific states (California, Oregon, Washington, Alaska, and Hawaii) lead all other sections of the nation with a per

*Absolute alcohol refers to the actual alcoholic content of a beverage. 
capita rate of 3.1 gallons of absolute alcohol. The lowest regional rate is that of the east south central states (Kentucky, Tennessee, Mississippi, and Alabama), which has a consumption level of 1.81 gallons per person. Arkansas has the lowest per capita rate (1.52.gallons) for an individual state, while New Hampshire ranks highest (5.42 gallons). Oregon ranks twenty-sixth among the states with a consumption rate of 2.67 gallons (Ibid., p. 3).

A series of four surveys was conducted by Harris and Associates (1974) in order to ascertain the percentage of drinkers in the population eighteen years of age and older. They found $42 \%$ to be "abstainers" or "infrequent arinkers," while $31 \%$ were classified as "light drinkers" (less than .22 ounces absolute alcohol per day). Another $18 \%$ were found to be "moderate drinkers" (.22 to 1.0 ounces absolute alcohol per day), and 9\% were "heavy drinkers" (more than 1.0 ounces absolute alcohol per day).

Several studies have been made which attempted to develop a profile of the kind of person most likely to have problems directly related to alcohol. These studies found that problem drinkers were more often less affluent men, separated, single, and divorced persons (in that order), persons with no religious affiliation, primarily beer drinkers, and residents of urban areas (Cahalan, 1970; Cahalan, Cisin, and Crossley, 1969; Cahalan and Room, 1974). The economic costs of alcoholism as represented by lost production, health and medical costs, motor vehicle 
accidents, alcohol programs and research, and costs to the criminal justice and public welfare systems are estimated to reach $\$ 60$ billion per year (Armour, Stambul, and Polich, 1976). In addition to this, drinking drivers represent between $40 \%$ and $55 \%$ of all fatally injured drivers, and make up 55\% to $65 \%$ of the drivers killed in single-car accidents (Keller, 1974, pp. 128, 130). Drinking drivers are also responsible for $45 \%$ of all pedestrian fatalities (Butler, $1974)$.

A number of studies have found substantially higher mortality rates for alcoholics as compared to the normal population (Davies, 1965; Schmidt and de Lint, 1972; Pell and D'Alonzo, 1973). A mortality ratio of $3.1: 1$ was found when the rates for these studies were averaged together.

Alcohol is the only recreational drug which is sanctioned by society at large. The state of Oregon maintains 186 state-operated and contract agencies for the distribution of packaged liquors and dessert wines. There are 2409 grocery stores in the state licensed to sell beer and wine, and 3390 taverns, restaurants, clubs, and cocktail lounges which sell alcohol by the drink. During fiscal year 1971-72, 1iquor sales in Multnomah County amounted to $\$ 88.30$ per capita, with a total figure of $\$ 32,735,686.00$ in sales during that period. The Comprehensive Alcohol Problems Plan for Oregon estimates the alcoholic population in the state at 67,492 persons. It is further estimated that 35,505 persons in Multnomah County are alcoholic. The actual 
Multnomah County population comprises approximately onethird of the state's population while containing $52.6 \%$ of the state's alcoholics. This indicates a high concentration of alcoholism in the county in relation to the rest of Oregon (Office of County Management, Multnomah County, 1976, p. 13) .

With such a large number of alcoholic persons in the Portland metropolitan area, the need for a well-developed treatment system is readily apparent. Within this system, a number of problems have been identified which are encountered in virtually all agencies. Among these is the high dropout rate both before and during treatment. At the Alcohol Treatment and Training Center, where the present study was conducted, a group intake system has been developed, which takes approximately six weeks to complete. A number of studies have been made which examine the characteristics of persons who leave agencies after a single intake session, but no study has examined the characteristics of persons who drop out of such an extensive intake process as at this agency. This study then, attempts to add one more piece to the highly complex puzzle of alcoholism in the hope that practitioners can make use of this information to help mitigate the effects of this most pervasive and destructive social problem. 
CHAPTER II

INTAKE

Intake may be defined as the process by which an applicant requests services of an agency, and the agency determines whether and what kind of services are to be provided (Siporin, 1975, p. 193). In general, the purposes of intake in an agency offering treatment services are the following: 1) To provide access services to people in need and to recruit clients ${ }^{*}$ to the agency (Ibid.).

2) To gather data on the applicant (demographic, psychological, financial, medical, etc.).

3) To determine whether the agency is appropriate for the applicant and, if not, to provide referral services.

4) To provide the client with information on the function of the agency, its treatment philosophy, and method(s).

5) To explain to the applicant the agency's expectations of him (time commitment, fee schedule, etc.).

6) To provide the client with an opportunity to express his reasons for seeking treatment and his expectations of treatment, and to help him tailor his expectations to reality.

* To avoid confusion, no distinction is herein made between an intake "applicant" and "client," the terms being used interchangeably. 
7) To explore with the applicant his feelings, both pro and con, concerning treatment.

8) To provide emotional first aid to the client and, thereby, ease his emotional strain and help him become more realistically oriented to his situation.

9) In some cases, to make a preliminary psychological asessment of the client.

10) When appropriate, to provide the client with technical information about his basic problem, e.g., alcoholism. 11) To negotiate and establish a service plan and contract between the applicant and the agency (Ibid., p. 194).

Intake may be carried out over the telephone or in person. The objectives and procedures of both forms of intake are basically the same, but there are some obvious limitations to telephone intake. It is more impersonal than inperson intake, and certain diagnostic information, such as nonverbal behavior, is unobtainable. Personality tests cannot be taken over the telephone, and questions on forms which could be answered by the applicant without assistance, were he there in person, must be asked by the intake worker, thus taking up more time.

In-person intake may be conducted individually or in a group setting. Each form has particular advantages and disadvantages. In individual intake the client receives the full attention of the intake worker and it, therefore, lends itself to a more in-depth interview than group intake, wherein the intake worker's attention is divided amongst 
several persons. It further permits a much shorter intake process for the client, since there is no waiting period for him while information is collected from others, as is the procedure in group intake.

There are certain disadvantages to individual intake. When an applicant does not appear for his session the intake worker's time may be wasted. It requires more staff time, and due to Iimitations in available staff there may be long waiting lists for intake. According to Gallant, stoy, Faulkner, and Paternostro (1966), many applicants interpret this delay as overt rejection or lack of concern (p. 349). Furthermore, a person applying for intake is often in a crisis state needing services immediately, and a delay in intervention may lead to maladaptations or breakdowns in his life situation (Perlman, 1960, p. 171). Following the waiting period, it may be discovered that the agency is not the appropriate resource for the applicant and he must be referred elsewhere, creating a still longer period of time before he receives treatment.

Lastly, individual intake has distinct disadvantages for persons seeking treatment for alcoholism. According to Gallant et al. (1966), when an alcoholic client has an individual intake session, his feelings of alienation may be compounded by the realistic loneliness he suffers as an only patient in a new treatment setting. In such a situation he tends to exaggerate his denial mechanism, and his hostility toward authority figures is aggravated by the submissive 
role assigned to him (p. 351).

In group intake, if one or more of the applicants fails to attend, those who do attend can still be served, thereby helping to avoid a waste of staff time. Though there may be a waiting period in order for enough persons making application to form an intake group, normally applicants are seen much sooner than in individual intake.

In group intake it may be easier for a client to begin facing his problems realistically after he has observed others doing so, and the support and encouragement of the other members can help him begin to constructively deal with his difficulties (Scott, Keener, and Manaugh, 1977, p. 147). Through the diversity of membership in the group, the client may learn of different ways of responding to his problems, and at the same time may come to identify himself with other members, thus reducing his possible feelings of alienation.

Group intake has two specific advantages in alcoholism treatment.programs. A client the intake worker believes has the most typical and lengthy history of alcoholism may be selected as the initial focus of the intake session, and may be

...encouraged to discuss freely his early symptoms of alcoholism and his subsequent addiction. The other patients are [thereby] offered the opportunity to identify with either the early, middle, or late stages of alcoholism, (Gallant et al., 1966, p. 350)

and are better able to understand their own symptoms. Secondly, an alcoholic is often able to easily use his denial 
mechanism with the intake worker in an individual intake, but "has difficulty maintaining this defense in the presence of . . other alcoholics" (Ibid., p. 351).

The two main disadvantages of group intake are that it takes up more of the client's time, and it lacks the privacy of individual contacts and the attention that some clients require (Siporin, 1975, p. 194).

The format of intake may be single-session or multisession. The latter more commonly applies to group intake. Single-session intakes have the advantage of requiring less of the client's time and potentially shortening his waiting period for treatment. Multi-session intakes have the possible advantage of screening out applicants. who are not sufficiently motivated for treatment. That is, it is assumed that applicants who are unable to complete a lengthy intake process would not likely complete an even lengthier treatment program. Multi-session intakes may thus spare an agency from wasting time in attempting treatment with probable dropouts. This format runs the risk, however, of screening out applicants who desire some immediate help with their problems but become discouraged by the extended intake process. 
PURPOSE OF STUDY

The primary purpose of this study conducted at the Alcohol Treatment and Training Center was to determine what demographic and personality characteristics, if any, distinguished intake process completers from noncompleters. It was anticipated that this information would provide intake workers at the Center with a guideline for assessing the dropout potential of clients seen at intake. It was further hoped that the information gathered during this study would provide the Center with suggestions for making alterations in the intake system to better accommodate clients with highrisk dropout characteristics.

Secondary purposes of the study were (1) to determine how the characteristics of the Center's intake process noncompleters compared with the characteristics of dropouts in previous pre-treatment and treatment dropout studies; and (2) to provide the administration of the Center with statistical information about their programs, e.g., the dropout rate and characteristics of the population they serve. 
CHAPTER IV

REVIEW OF LITERATURE: PRE-TREATMENT AND TREATMENT DROPOUT STUDIES

A review of the Iiterature revealed only one study comparing persons who attended the first session of alcoholism treatment following intake, with those who did not attend. Only four such studies were found for general psychotherapeutic treatment. The process of intake, discussed in the five studies, was conducted in one of two forms:

(1) telephone intake, where the individual makes application for treatment and gives biographical and other information over the telephone to the intake worker; and (2) in-person intake, where the individual applies for treatment (usually by telephone) and is given an appointment with an intake worker who he sees in person.

Wanberg and Jones (1973) made a comparative study of persons attending and not attending alcoholism treatment following telephone intake, on fifty-five different variables. These included "age, sex, social-cultural and socioeconomic descriptions, religion, employment status, treatment history, marital status, [and] referral sources" (p. 282). Of the fifty-five variables studied, only five were found to significantly differentiate the two groups. Variables related to not showing for treatment were affiliation 
with a major Protestant church, self-referral for treatment, and a waiting period of eight days or more between intake and the first session of treatment. Variables related to showing for treatment were having a family physician and motivation for treatment (as judged by the intake staff). Gould, Paulson, and Daniels-Epps (1970), in their study of persons attending and not attending initial sessions of psychotherapy after telephone intake, found no relationship between the length of the waiting period (between intake and the start of treatment) and showing or not showing for treatment. They did, however, find that persons "with the most clearly defined reasons for seeking help [tended] to show up, while those persons with the vaguest reasons [tended] not to" (p. 524).

Noonan (1973), in another study of persons keeping and failing to keep their appointment for the first session of psychotherapy following telephone intake, similarly, found no significant difference between the two groups with regard to the length of the waiting period for treatment. He also found no significant differences between groups for age, number of years of education, marital status, and sex (p. 43). As with Gould et al. (1970), he found the two groups to differ in the descriptions they gave of the problems for which they were seeking treatment. Those who did not keep their appointments tended to give vague or evasive statements of their problems (e.g., "a personality problem"), whereas, those who did keep their appointments tended to 
state their problems as specific and personal.

In an in-person intake study, Gibby, Stotsky, Miller, and Hiler (1953) collected data on male patients at a Veteran's Administration mental health clinic who, (1) completed intake but subsequently refused treatment, (2) dropped out of treatment within the first five sessions, and (3) had been in treatment for at least six months. The only differences between the first and second groups were in race (the former were more often Black) and a few Rorschach criteria. * Differences between the first and third groups were found for the following: the first group consisted of people who more often were Black, presented somatic symptoms as initial complaints more often, and, according to Rorschach scores, were less motivated for therapy, less cooperative, and more suppressive of their anxiety.

It must not be assumed that pre-treatment dropouts are necessarily rejecting treatment, as they might enter treatment elsewhere, or at a later time at the same clinic. Brandt (1963), attempting to control for these factors, made a psycholinguistic study of the statements of problems of "rejectors" of psychotherapy (those persons who were seen at intake but subsequently refused treatment at that clinic, and did not seek therapy elsewhere within the following four months) and "acceptors" of psychotherapy (those persons who

* Specific Rorschach criteria differences between these two groups were not discussed. 
were seen at intake and began treatment at that clinic). Matching the two groups by age, sex, education, previous psychotherapy, and socioeconomic status (all were designated lower middle class), he found that rejectors

...tended to present problems as lying in the environment rather than within themselves, and when presenting the problems in writing used fewer words and less verbs than acceptors. (Brandt, 1965, p. 10)

In comparing them on data collected prior to matching on the above characteristics, he found that rejectors had slightly more education and fewer had had previous therapy than acceptors (Ibid.).

Several studies have been made of the percentage of people who go through intake but do not begin treatment. Three such studies were made for alcoholism treatment programs. Mayer, Needham and Myerson (1965), and Wanberg and Jones (1973), both studying individual in-person intake, found a no-show rate of $38 \%$ and $34 \%$, respectively. Gallant, Bishop, Stoy, Faulkner, and Paternostro (1966) found a noshow rate of $54 \%$ for individual in-person intake, and a $36 \%$ rate for group intake.

In the pre-treatment dropout studies for psychotherapy applicants, the no-show rate following individual in-person intake ranges between $20 \%$ and $30 \%$ (Gould et al., 1970, p. 529). Following telephone intake, Gould et al., (1970) found a no-show rate of $44 \%$ (p. 529). With regard to the percentage of psychotherapy pre-treatment dropouts who are "pseudorejectors," i.e., enter treatment elsewhere, Brandt (1964) 
found, in a four month follow-up study, that only 37 or the 100 persons not showing for psychotherapy

...stated that they had changed their minds about undergoing this form of treatment and had not applied for it elsewhere ... [while 63 of them] stated that they had entered psychotherapy elsewhere. ( $p .311$ )

It is not known whether this pseudorejection is as prevalent among alcoholism pre-treatment dropouts, due to the absence of any follow-up studies.

Goucher (1949), in a study of two groups of veterans, (1) those who did not show up for psychotherapy following intake, and (2) those dropped out at some point during treatment, attempted to correlate the reasons for terminating treatment with the point at which treatment was terminated. She found no significant correlations and suggested that such findings indicate that "the patient does not distinguish between intake and therapy interviews since in both he has to reveal himself" (Brandt, 1965, p. 10).

Assuming Goucher's reasoning to be correct, the authors include here a review of the studies of treatment dropouts. Those relevant to the present study fall into four categories: (1) outpatient alcoholism treatment dropout studies, (2) inpatient alcoholism treatment dropout studies, (3) group psychotherapy dropout studies, and (4) individual psychotherapy dropout studies.

Baekeland and Lundwall (1975) have made a thorough literature review in these four areas and have summarized the findings of those studies which they considered to be 
supported by acceptable statistical analyses and tests of significance. In their summary of nine studies of outpatient alcoholism treatment dropouts they state that dropouts, in relation to persons remaining in treatment, were of lower socioeconomic status (as measured by education, income, and occupational status), tended to be single or, if married, separated from their spouse, as well as socially isolated in general. They more often were ambivalent toward treatment, had a history of dropping out of treatment, had a history of arrests, had poor social stability, especially with regard to occupation, and were more often legally coerced into treatment. They tended to be poorly motivated, highly symptomatic, more counterdependent, ${ }^{*}$ more field dependent, ** more autonomous, less deferent, and more often had sociopathic features (Baekeland and Lundwall, 1975, pp. $750-51)$

The findings of an outpatient alcoholism treatment study made following publication of Baekeland and Lundwall's (1975) review, by Heinemann, Moore, and Gurel (1976) are consistent with the above summary. In another later study,

* Counterdependent individuals "are resistant to proffered help, insist on their ability to do things for themselves, feel that they do not need anything, and do not believe in the utility of trusting others" (Baekeland and Lundwall, 1975, p. 750).

** Field dependence "refers to a cognitive style associated with a poorly differentiated self-concept and reliance on primitive defenses such as denial and repression" (Ibid., p. 751). 
however, by Rosenberg and Liftik (1976), it was found that legally coerced patients tended to remain in treatment longer than voluntary patients, which is incongruent with Baekeland and Lundwall's summary.

The dropout rate for the first month of outpatient alcoholism treatment generally ranges between $52 \%$ and $75 \%$ (Baekeland and Lundwall, 1975, p. 749).

Summarizing the literature on studies of inpatient alcoholism treatment dropouts, Baekeland and Lundwall (1975) report that dropouts tended to be younger, in a more advanced stage of alcoholism, more autonomous, more independent of environmental stimuli, more aggressive, more defensive, more socially dependent, though more socially isolated and unaffiliated, less mature, less responsible and less emotionally controlled. Dropouts, further, tended to make more use of denial, have less self-esteem and more selfdoubt, did not form close relationships quickly, and relied on alcohol for relieving feelings of resentment, anxiety, or depression (pp. 749-50).

Not mentioned in their review were three studies comparing inpatient alcoholism treatment dropouts with remainers on the Edwards Personal Preference Schedule scales (Edwards, 1959). In a study by Fitzgerald, Pasewark, and Tanner (1967), dropouts were found to differ from remainers on the autonomy, affiliation, aggression, and dominance scales, though the biserial correlations were quite low $(.19, .12$, 
.14 and .32, respectively)." In later studies by Pryer and Distefano (1970) and Gross and Nerviano (1973), no significant differences were found between dropouts and remainers for any of the scales.

The dropout rate in inpatient alcoholism treatment is a great deal lower than that for outpatient alcoholism treatment, the former ranging between $14 \%$ and 398 (Baekeland and Lundwall, 1975, p. 749).

With regard to group psychotherapy, very few studies have been made comparing dropouts with remainers. Summing up the little data available, Baekeland and Lundwall (1975) state that the dropout tends to be female, with paranoid features, low levels of anxiety, low social effectiveness, and lacking in psychological mindedness (p. 759). The dropout rate ranges between $25 \%$ and 508 (Yalom, 1966, p. 393).

The majority of treatment dropout studies have been made on individual psychotherapy patients. In summarizing sixty-two of such studies, Baekeland and Lundwall state:

...the patient most likely to drop out is an unaffiliated, lower socioeconomic status female who may either have paranoid or sociopathic features and enters treatment with low levels of anxiety and/or depression. Poorly. motivated, she is not very psychologically minded, tends to use a high degree of denial, and has problems in the area of dependent strivings which may take the form of either overt behavioral dependence or countertransference. (Baekeland and Lundwall, 1975, p. 759).

\footnotetext{
* The authors did not state how dropouts differed from remainers on these characteristics.
} 
Additionally, they report that dropouts were more often institutionally-referred than self- or physician-referred, and that age is also predictive of dropping out of treatment, though the relationship is complex. That is,

... in brief (six session) therapy, younger patients were more likely to drop out ... while in long-term treatment patients younger than 30 or older than 39 years of age were more likely to be lost ... On the other hand, in a clinic with many general hospital referrals, older patients dropped out sooner ... perhaps because hospital-referred patients (who are more likely to drop out) are older than those who are self-referred. (Ibid., p. 755)

In individual psychotherapy $20 \%$ to $57 \%$ of the patients do not return for a second visit, and $31 \%$ to $56 \%$ do not attend more than four times (Ibid., p. 738).

In the following chapters the authors turn to a discussion of the present study: the two objective schedules employed, the clinical setting, and the characteristics of the clinic's population. 
INSTRUMENTS USED IN STUDY: THE EDWARDS PERSONAL PREFERENCE SCHEDULE AND THE SCHEDULE

OF RECENT EXPERIENCE

The Edwards Personal Preference Schedule (EPPS) was designed by Allen L. Edwards of the University of Washington, to study personality with regard to its normal, rather than abnormal, manifestations. The schedule purports to measure the strength of fifteen different human needs: (1) achievement, (2) deference, (3) order, (4) exhibition, (5) autonomy, (6) affiliation, (7) intraception, (8) succorance, (9) dominance, (10) abasement, (11) nurturance, (12) change, (13) endurance, (14) heterosexuality, and (15) aggression. The EPPS follows the "forced-choice" format, requiring the subject to choose between two descriptive phrases, representing two different human needs, as to which is more characteristic of him. The two phrases were designed to be equally acceptable, thus, minimizing the influence of social desirability on the subject's choice, a common problem of the traditional inventory which asks for a "yes" or "no" response. An example of one of the paired statements on the EPPS is the following :

A I like to help my friends when they are in trouble.

B I like to do my very best in whatever I undertake. The former statement applies to the need to nurture others, 
and the latter applies to the need for achievement. After choosing on 225 of such paired statements (each of the fifteen needs is paired twice with each of the other needs), it becomes clear from the scoring, the degree to which each of the needs is important to the subject.

To check for validity of the subject's responses, the EPPS has a "consistency" score, which is measured by comparing "the number of identical choices made in two sets of the same 15 items" (Edwards, 1959, p. 15).

No studies were found in the literature using the EPPS in pre-treatment dropout studies, though three studies were located using the schedule with treatment dropouts. The results of these studies were discussed in Chapter IV in relation to inpatient alcoholism treatment dropout studies.

The Schedule of Recent Experience (SRE) was developed by two physicians, Thomas H. Holmes and Richard H. Rahe, both from the University of Washington School of Medicine. It was designed to study the relationship between events in a person's life requiring readjustment, e.g., the death of a spouse, and the onset of physical illness. Through earlier studies they developed a scoring system for forty-two different life events which measures the degree of life readjustment necessary to accommodate the event. Death of a spouse was determined the life event requiring the greatest degree of readjustment, and was assigned a score of 100 . Divorce, next in order of magnitude, was assigned a score of 73. The event category with the least degree of readjustment 
necessary was minor violations of the law, and was designated a score of 11. (See Table I for the complete list of life events and their scores.)

The SRE determines which of the forty-two life events are affecting the subject and the scores for each event are added up for a grand total. The higher the person's score, the more change is going on in the person's life. They found in numerous studies that the higher the person's score, the: more likely it would be for him to become physically ill, and concluded that life change lowers a person's resistance to disease.

A recent study was made by Mules, Hague, and Dudley (1977), of the relation between scores on the SRE and alcohol addiction of ten or more years. They found that hospitalized alcoholics had significantly higher scores on the SRE than a comparable population of non-alcoholic, medicalsurgical hospital patients. They also found a positive correlation between high SRE scores and greater severity of alcohol addiction.

Considering this latter finding along with the finding of a positive correlation between a person's severity of addiction and his likelihood to drop out of treatment (as noted in the discussion in chapter IV on inpatient alcoholism treatment dropouts), then it is probable that there would be a relation between a person's SRE scores and whether or not he drops out of treatment for alcoholism. No studies considering such a hypothesis, however, were located. 
TABLE I

THE SCHEDULE OF RECENT EXPERIENCE

\begin{tabular}{|c|c|c|c|c|c|c|c|c|c|}
\hline RANK & IIFE & EVENT & & & & & & & VALUE \\
\hline 1 & Death of spouse. & - & - & - & - & - & - & • & 100 \\
\hline 2 & Divorce . . . . . . . . & - & . $\cdot$ & - $\quad$. & - $\cdot$ & - & - & - & 73 \\
\hline 3 & Marital separation & - $\cdot$ & $\cdot \cdot$ & - & . $\bullet$ & - & - & - & 65 \\
\hline 4 & Jail term : • • • • & • • • & - $\cdot$ & - - & - $\bullet$ & - & - & - & 63 \\
\hline 5 & Death of close family me & ember & - $\cdot$ & - . & - $\cdot$ & - & - & - & 63 \\
\hline 6 & Personal injury or iline & ess & . . & . $\bullet$ & . . & - & - & - & 53 \\
\hline 7 & Marriage $. \cdot . \cdot . \cdot . \cdot$ & 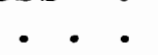 & .. & - $\quad$. & . . & • & • & - & 50 \\
\hline 8 & Fired at work . & - & - $\cdot$ & - & - & - & - & - & 47 \\
\hline 9 & Marital reconciliation & & - $\quad$ - & & & & - & - & 45 \\
\hline 10 & Retirement . . • . . . & & . $\cdot$ & - $\cdot$ & - $\cdot$ & • & - & - & 45 \\
\hline 11 & Change in health of fami & ily mem & nber & & & & - & - & 44 \\
\hline 12 & 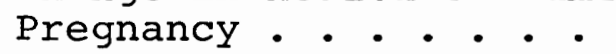 & .. & . . & .. & - $\cdot$ & - & - & . & 40 \\
\hline 13 & Sex difficulties . • . & • • • & - $\cdot$ & - & - $\cdot$ & - & - & - & 39 \\
\hline 14 & Gain of new family membe & er. & & • & - & 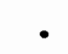 & • & - & 39 \\
\hline 15 & Business readjustment . & - $\bullet$ & - & - $\cdot$ & - & - & - & - & 39 \\
\hline 16 & Change in financial stat & Le & & - & - & - & - & 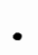 & 38 \\
\hline 17 & Death of close friend. & • & & 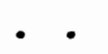 & - $\cdot$ & & - & - & 37 \\
\hline 18 & Change to different line & of wo & ork & • & - & & 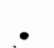 & - & 36 \\
\hline 19 & hange in number of argu & aments & with & spo & & 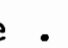 & . & . & 35 \\
\hline 20 & Mortgage over $\$ 10,000$. & $\cdot \cdot \cdot$ & - $\cdot$ & - $\quad$ & - $\cdot$ & - & - & - & 31 \\
\hline 21 & Foreclosure of mortgage & or loa & an . & - & • & 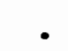 & • & - & 30 \\
\hline 22 & Change in responsibiliti & es at & work & - & - & 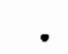 & • & & 29 \\
\hline 23 & Son or daughter leaving & home & - $\cdot$ & - & . $\cdot$ & - & - & 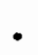 & 29 \\
\hline 24 & Trouble with in-laws & 年 & . $\quad$ - & - & $\therefore$ & & • & • & 29 \\
\hline 25 & Outstanding personal ach & ieveme & ent & & - & & • & • & 28 \\
\hline 26 & Wife begin or stop work & .. & .. & • & - & - & . & 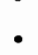 & 26 \\
\hline 27 & Begin or end school .. & - • • & - $\bullet$ & - & - & • & - & • & 26 \\
\hline 28 & Change in living conditi & ons. & & - & - & & • & • & 25 \\
\hline 29 & Revision of personal hab & its & & - & & & • & & 24 \\
\hline 30 & Trouble with boss . . & -. & & - & . & & • & & 23 \\
\hline 31 & Change in work hours or & condi & Eion & 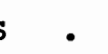 & • & & • & & 20 \\
\hline 32 & Change in residence . . & & - $\cdot$ & 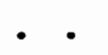 & - & & 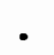 & & 20 \\
\hline 33 & Change in schools . . . & 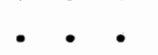 & - $\cdot$ & - & - & 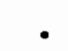 & - & • & 20 \\
\hline 34 & Change in recreation & & & $\bullet$ & - & $\bullet$ & - & - & 19 \\
\hline 35 & Change in church activit & ies & & $\bullet$ & & & - & & 19 \\
\hline 36 & Change in social activit & ies & & 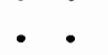 & • & 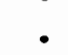 & • & & 18 \\
\hline 37 & Mortgage or loan less th & $\operatorname{lan} \$ 1$ & & & - $\cdot$ & & 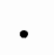 & & 17 \\
\hline 38 & Change in sleeping habit & & - $\cdot$ & 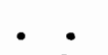 & - $\cdot$ & & ( & . & 16 \\
\hline 39 & Change in number of fami & $1 y$ & & ecile & ers & & & & 15 \\
\hline 40 & Change in eating habits & -2 & 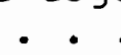 & 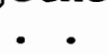 & & 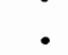 & - & & 15 \\
\hline 41 & Vacation $\cdot$. . . . & - $\bullet$ & & - & & - & - & & 13 \\
\hline 42 & Minor violations of the & law. & & - $\cdot$ & & - & - & • & 11 \\
\hline
\end{tabular}


CHAPTER VI

THE ALCOHOL TREATMENT AND TRAINING CENTER

The Alcohol Treatment and Training Center is an outpatient facility operated by the Alcohol and Drug section of the Oregon Mental Health Division. It is the major publicly supported agency in the Portland metropolitan area which provides both psychologically-oriented treatment to persons with alcohol-related problems, and training for workers in the field of alcoholism. Established in 1950, the Center now serves a population of approximately 500 alcoholics and their spouses.

There is no financial, geographic, or other type of requirement for eligibility for services at the Center. All services are provided free of charge, although drugs, such as antabuse, which may be a part of individual treatment plans, must be purchased by the client from retail pharmacies.

Due to a relatively small operating budget and a need to provide services at the lowest possible cost-benefit ratio, the paid professional staff of the Center is augmented by volunteers. Aside from administrative and clerical personnel, there are only four paid staff members filling direct service positions, and much of the time of these workers is involved with training tasks. 
The Center has taken several steps to attempt to provide a full range of services in spite of the restrictions imposed by its budget. These include: (1) an emphasis on group rather than individual therapy, (2) the initiation of a group intake system, (3) the use of volunteer intake workers and therapists and, (4) the use of administrative and support personnel in the treatment process.

Persons seeking treatment at the center initially contact the receptionist either by telephone or in person. At this time the application process is briefly explained to the applicant and he is assigned to an intake group. Groups are held both during the day, and in the evenings to facilitate the attendance of working clients. Spouses are encouraged to attend throughout the Center's program beginning with the intake groups. Between ten and fifteen clients are scheduled for each intake group, with an average attendance rate at the first group session of approximately $50 \%$. Depending on the number of persons requesting treatment at any given time, the waiting period from the initial contact to the first intake session may vary from one day to several weeks. A waiting period of one week is considered to be average. Intake groups usually consist of three ninety minute sessions. Occasionally, if the aropout rate for a particular group is low, this is extended to four sessions to allow the worker sufficient time to gather the necessary information. Groups are held once a week, making three weeks the minimum length of time necessary to complete this 
portion of the intake process. During this period, persons are also asked to complete two tests, the Edwards Personal Preference Schedule and the Schedule of Recent Experience. The content of the group intake sessions includes orientation to the Center's intake process and treatment programs, dissemination of basic information about alcohol and alcohol addiction, and the collection of a wide range of demographic, psychological, and historical information on each client. Intake groups are conducted by regular staff members, and volunteers who have received specialized training at the Center. These intake workers are virtually always members of the middle class. In a few cases individual intake sessions are scheduled for clients who have particular problems which cannot be dealt with in a group setting. This happens on an infrequent basis and is not encouraged by the center administration, as it is believed that "special treatment generally leads to unrealistic attitudes and a poorer-than-average prognosis" (Scott, Keener, and Manaugh, 1977, p. 144).

Once the group intake sessions are completed, the client is scheduled for staffing. During staffing the client is interviewed by a group of between five and fifteen professional and volunteer staff members who identify the person's significant problems and decide upon a treatment plan. At this time a psychiatric diagnosis is also made.

At staffing the client is assigned to one of approximately fifteen therapy groups. Occasionally a client who 
needs special attention will be scheduled for several individual sessions prior to entering a group. An attempt is made to tailor the type of group to the needs of the particular client. Specialized groups have been developed for single persons, couples, wives of alcoholics, homosexuals, and elderly persons, as well as for clients with specific types of psychological problems (e.g., schizophrenic groups and sociopathic groups).

Referrals to other community agencies are generally made either during the group intake process or at staffing. This is done infrequently as it seems that only a few staff members (most notably the professional social workers) are aware of the value of the referral process.

The length of time between the client's initial contact and the first session of treatment is approximately six weeks. The Center staff believes that this lengthy application period serves as a test of the client's motivation for treatment.

There are several major points of attrition throughout the intake process. The first of these is prior to the first session of intake. A preliminary investigation by the authors of this study found a $53.7 \%$ no-show rate for the first intake session. The second point of attrition is during the group intake process itself. A number of persons do not return after the first group session, or if they do complete all group meetings, do not appear for staffing. A smaller number drop out after staffing. The dropout rate 
for those who are seen at least once is $64 \%$. This does not include clients who arop out of treatment. 
CHAPTER VII

THE CENTER POPULATION

A random sample drawn from the population of persons who had completed the intake process and were, at the time of the study, receiving treatment at the center was used as the control group for this study. This sample provided a good deal of information regarding the characteristics of clients being served by this agency. All subjects chosen had a primary diagnosis of alcoholism. Non-alcoholic spouses were not included in the sample.

The population of the Center was found to be primarily male ( $87 \%$ ) and the average age, 38.30 years. Of the 46 subjects examined, 11 (24\%) had never married, 21 (46\%) were currently married or remarried, and 14 (30\%) were divorced, separated, or widowed. The average number of dependents for the members of the sample was 2.15 . Racially, only $15 \%$ belonged to minority groups (Black, American Indian, and Chicano) while $85 \%$ were white. Seventy-seven percent were economically self-supporting, with $23 \%$ being supported by the public welfare system (General Assistance, AFDC, Social Security, and Veteran's pensions).

An interesting breakdown was seen when income level was examined. One group of clients clustered around the lower end of the scale. of the total sample. 37\% had a 
family income of less than $\$ 6,000$ per year and $22 \%$ made less than $\$ 3,000$. The remainder of the subjects (63\%) made over $\$ 7,000$ per year, with $22 \%$ being in the highest category of $\$ 15,000$ plus. This bimodal distribution indicated two distinct subcategories of clients, one very poor group and one group of middle class persons.

In terms of education the population was more evenly distributed. All but two clients had at least completed elementary school. Eleven persons (24\%) had had some high school, and twelve (27\%) were high school graduates. Another 12 (27\%) had attended college, and two (4\%) had received a bachelor's degree. One subject (2\%) possessed an advanced degree, and three others (7\%) had completed a business or technical s.chool program.

The majority of those studied were currently employed (57\%), with $43 \%$ being unemployed at the time the sample was drawn. Twenty-five percent of the sample were professional or white collar workers, $41 \%$ were skilled laborers, and $34 \%$ were unskilled laborers.

Seventy percent of the sample had a history of arrests for driving while intoxicated, the average number of arrests being 2.34. A majority of the subjects (54\%) were referred to the Center by the legal system (court or attorney). Most of the rest were referred by self, family; or friends (24\%). The remaining $22 \%$ were referred by a variety of individuals and agencies within the community, such as social service 
agencies, private practicing physicians, private mental hospitals, and general hospitals.

A slight minority (48\%) had received previous treatment for alcohol-related problems. About a third (35\%) reported having at least one alcoholic parent.

The Center population was compared statistically to the general adult population on the Edwards Personal Preference Schedule (EPPS) variables (see Table II, p. 47). Statistically significant differences were found on eight of the fifteen scales. The sample scored significantly higher on heterosexuality $(z=6.41 ; p<.01)$, change $(z=3.55$; $\mathrm{p}<.01)$, exhibition $(\mathrm{z}=3.37 ; \mathrm{p}<.01)$, and intraception $(z=4.21 ; p<.01)$. Significantly lower scores were recorded for endurance $(z=-2.58 ; p<.01)$, deference $(z=-3.60$; $\mathrm{p}<.01)$, order $(\mathrm{z}=-3.28 ; \mathrm{p}<.01)$, and affiliation $(\mathrm{z}=-1.80$; $\mathrm{p}<.05)$.

In a. previous study comparing alcoholism treatment inpatients with the normal population on the EPPS scales, Fitzgerald, Pasewark, and Tanner (1967) found male alcoholics to score lower on exhibition, autonomy, and succorance, and higher on deference and endurance than the general adult male population. They found female alcoholics to score lower on exhibition, intraception, and heterosexuality than the general adult female population.

The sample scored relatively high on the schedule of Recent Experience, when life change of the past three years was assessed. A mean score of 1432.60 was found, which 
would suggest both a propensity for increased incidence of physical illness and a high level of psychological stress. 
CHAPTER VIII

METHODOLOGY

Experimental Design and Sample Selection

The study employed an experimental design which was developed to permit a nonbiased comparison of intake process completers and noncompleters on a number of demographic and psychological variables. For this purpose, two groups of subjects were selected, a control group consisting of persons who had completed the intake process and had begun treatment, and an experimental group of persons who had dropped out of the process prior to the first treatment session.

Specific criteria were developed for inclusion of subjects in the sampling frames for both groups. In order to be considered for selection as a member of the control group (intake process completers), subjects were required to meet five criteria: (1) satisfactory completion of the group intake process, (2) having their case "open" at the time the sample was drawn, (3) a primary diagnosis of alcoholism (non-alcoholic spouses were excluded), (4) initiation of treatment after January. 1, 1977, and (5) attendance of at least one group therapy session. At the time the sample was drawn 87 clients met these criteria, and of these, 50 were randomly selected through the use of a random 
number table to comprise the control group. Four of these subjects were subsequently discovered to not be alcoholic and were dropped from the study, leaving a final sample size of 46 .

In order to be included in the experimental group (intake process noncompleters), four criteria had to be met: (1) attendance of at least one group intake session, (2) a primary diagnosis of alcoholism, (3) termination of the intake process prior to the first session of treatment, and (4) failure to reapply for treatment within three months. Due to the limited number of persons making application for services, time constraints required the inclusion of all subjects who met these criteria in the experimental group. Therefore, the sample contained all persons who dropped out of the intake process between July 20, 1977 and October 31, 1977. It is believed that the temporal relationship between the selection of the two groups is close enough to obviate any significant degree of bias related to time and subject maturation or change. Assignment to this group was completely random and no subjects were systematically excluded for any reason. A number of subjects were, however, dropped from the group when the intake worker failed to collect the data required for comparison to the control group. This was the case with one or two intake workers on a consistent basis and it is believed that this does not bias the sample due to the random assignment of clients to these workers. As an additional check against interviewer bias, dropout 
rates for individual intake workers were compared. No significant differences were discovered. Subjects were assigned to intake groups according to the normal clinic procedure of placing clients in regularly scheduled groups on a first come first served basis. No client received any differential treatment other than that related to the individual differences in the styles of intake workers.

\section{Data collection}

During the data collection phase of the study, care was taken to modify the existing intake system as little as possible. The major change was in having intake workers consistently gather more demographic information on the experimental group in the first group intake session. Since intake workers are normally free to gather this information whenever they wish, our request represented a change in practice for some workers and no change for others. Because a significant portion of the noncompleters terminated immediately after the first intake session, it was essential that the information be collected at this time. In some cases, data was collected at subsequent sessions when either the client failed to appear at the first group meeting, or for some reason the intake worker was unable to get all the information in the first session. Clients were asked to take the Edwards Personal Preference Schedule (EPPS) and the Schedule of Recent Experience (SRE) before the first intake session so that this data would be available for comparison 
to the control group. As was expected, difficulties were experienced with the completion of these tests. A number of persons did not finish the tests until after they had begun intake, and although the completion rate for the EPPS was fairly high (77\%), only $44 \%$ of the sample completed the SRE, making comparison with the control group difficult.

Data on the control group was taken from completed charts in the Center's open files and entered directly on a main data sheet. To protect the confidentiality of the subjects, no individual was identified by name on this data sheet and the list of names of persons selected for the control group was destroyed as soon as the data was coded and entered on the sheet. A similar process was followed for the experimental group although it was necessary here to retain the list of names until the three month reapplication period was over.

The forms used for data collection were those already in use at the center. Information on age, sex, marital status, ethnic group, source of income, income level, and educational level was collected by the intake worker and entered on the Data Sheet (CL-1), which is a form used by most Oregon Mental Health Division agencies for routine reporting of characteristics of their populations. A selfreporting form developed by the Center labeled "Personal History Form" was used to gather data on a number of variables including: occupation, current employment, number of arrests for ariving while intoxicated, referral source, 
previous treatment, alcoholic parents, and legal coercion. Diagnostic information regarding the phase of addiction was taken from a list of diagnostic criteria developed by the Criteria Committee of the National Council on Alcoholism which were checked by the intake worker as they applied to the particular client being interviewed. Scores on the EPPS and the SRE were taken from the answer sheets for those tests.

Once all the data was entered on the main data sheet, appropriate sample statistics were computed for both control and experimental groups. These statistics were then compared through the technique of hypothesis testing to determine which demographic and psychological variables would differentiate the two groups with a reasonable margin of sampling error. It was decided to apply the most rigorous tests possible to the data and, therefore, only results with probable errors of 5 \% or less $(p<.05)$ will be reported in the following chapter. 
CHAPTER IX

RESULTS

Of the thirty-three variables examined in the study, twelve were found to distinguish intake process completers from noncompleters with statistical significance (see Table II). Noncompleters were found to be significantly younger $(z=2.25 ; p<.02)$ than completers, with mean ages of 32.29 and 38.30 respectively.

Noncompleters were more frequently never married, divorced, separated, or widowed than completers $(z=3.60$; $\mathrm{p}<.01)$. Noncompleters also tended to be Caucasian, rather than members of minority groups $(z=-3.00 ; p<.01)$, although this finding must be considered in light of the small number of minorities in both samples.

Another finding of the study was the lower socioeconomic status (SES) of the noncompleter group. SES was measured by three variables, income level, educational level, and occupational status. Noncompleters had significantly lower incomes $(z=2.05 ; p<.05)$, were more often high school or earlier dropouts $\left(x^{2}=6.56, d . f .=1 ; p<.02\right)$, and were found to be more often unskilled laborers $(z=-4.18$; $\mathrm{p}<.01)$

The experimental group reported more severe alcoholic symptomatology $(z=2.50 ; p<.01)$. This group more often met 
the criteria developed by the National Council on Alcoholism for diagnosis of classical alcoholism.

Those who did not complete the intake process were significantly more often coerced into treatment by pressure from the legal system $(z=-4.80 ; p<.01)$. These individuals applied for treatment either in response to a suggestion from their attorney prior to a court appearance for an alcohol-related offense, or as a condition of probation or parole following conviction on such a charge.

Noncompleters were found to differ from the control group on three scales of the Edwards Personal Preference Schedule. The experimental group scored significantly higher on autonomy $(t=1.66, d . f .=72 ; p<.05)$, and aggression $(t=2.60, d . f .=72 ; p<.01)$ and significantly lower on deference $(t=2.56, d . f .=72 ; p<.01)$. Noncompleters were also found to have a lower consistency score on the EPPS $(t=12.30, d . f .=72 ; p<.01)$. 
TABLE II

SUMMARY OF FINDINGS FOR CONTROL AND EXPERIMENTAL GROUPS

Sex

\begin{tabular}{|l|c|c|c|c|}
\hline \multirow{2}{*}{} & \multicolumn{2}{|c|}{ Control } & \multicolumn{2}{c|}{ Experimenta] } \\
\cline { 2 - 5 } & $f$ & 8 & $f$ & $\%$ \\
\hline Male & 40 & 87 & 30 & 86 \\
\hline Female & 6 & 13 & 5 & 14 \\
\hline
\end{tabular}

Age

(Mean)

\begin{tabular}{|c|c|}
\hline Control & Experimental \\
\hline 38.30 & 32.29 \\
\hline$n=46$ & $n=35$ \\
\hline
\end{tabular}

Marital

Status
$n=46$
$\mathrm{n}=35$

\begin{tabular}{|c|c|c|c|c|}
\hline \multirow{2}{*}{} & \multicolumn{2}{|c|}{ Control } & \multicolumn{2}{c|}{ Experimental } \\
\cline { 2 - 5 } & $f$ & $q$ & $f$ & 8 \\
\hline Never Married & 11 & 24 & 18 & 51 \\
\hline $\begin{array}{c}\text { Married/Remarried/ } \\
\text { Non-Legal }\end{array}$ & 21 & 46 & 10 & 29 \\
\hline $\begin{array}{c}\text { Divorced/Separated/ } \\
\text { Widowed }\end{array}$ & 14 & 30 & 7 & 20 \\
\hline
\end{tabular}

$n=46$

$\mathrm{n}=35$

Ethnic

Group

\begin{tabular}{|l|c|c|c|c|}
\hline \multirow{2}{*}{} & \multicolumn{2}{|c|}{ Control } & \multicolumn{2}{c|}{ Experimental } \\
\cline { 2 - 5 } & $\mathrm{f}$ & $\circ$ & $\mathrm{f}$ & 8 \\
\hline White & 39 & 85 & 30 & 91 \\
\hline Non-white & 7 & 15 & 3 & 9 \\
\hline
\end{tabular}

$$
\mathrm{n}=46 \quad \mathrm{n}=33
$$




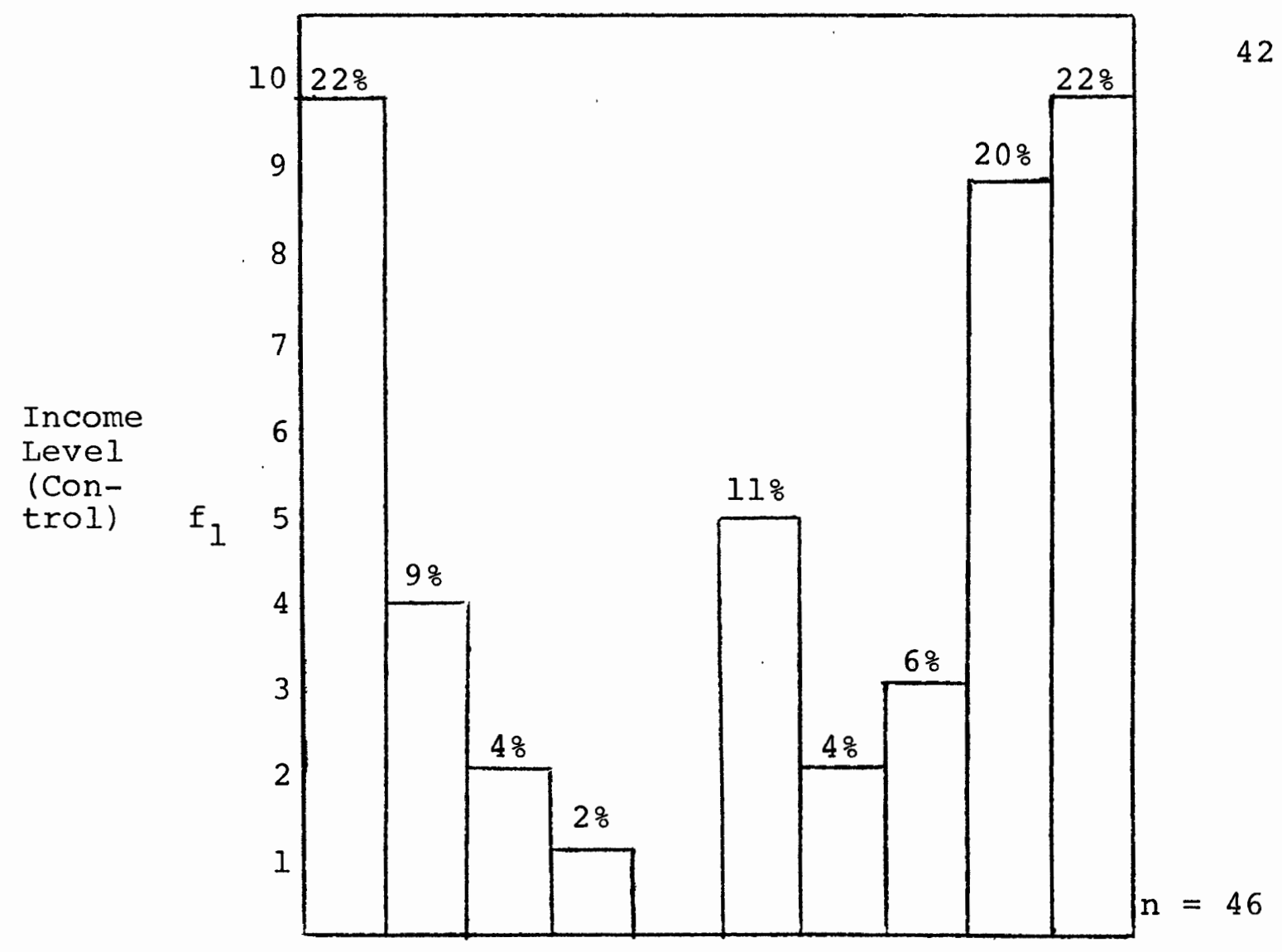

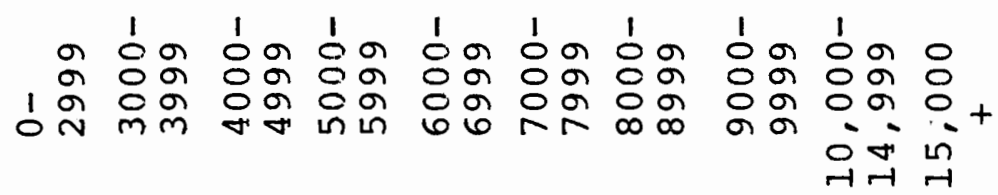

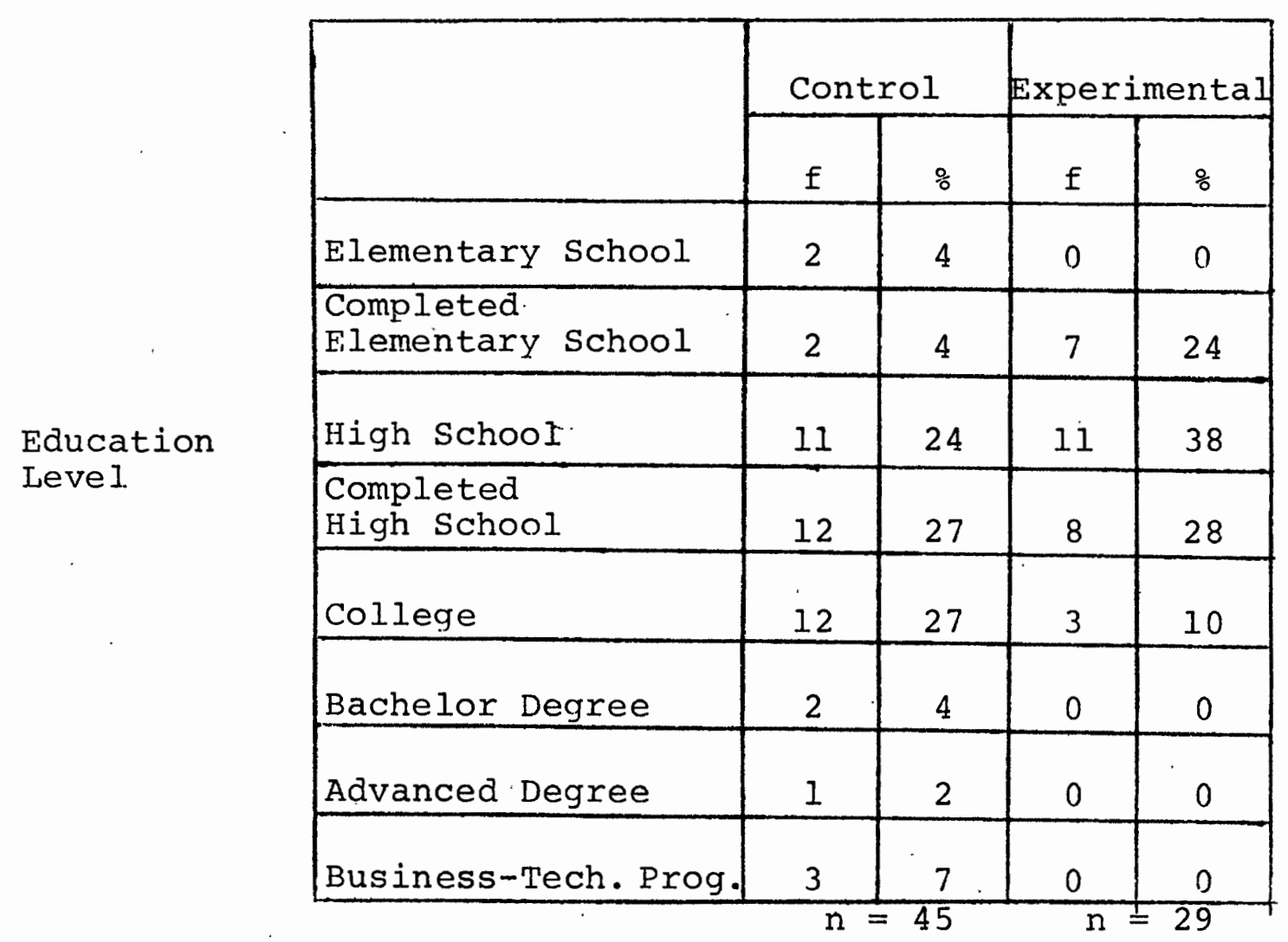




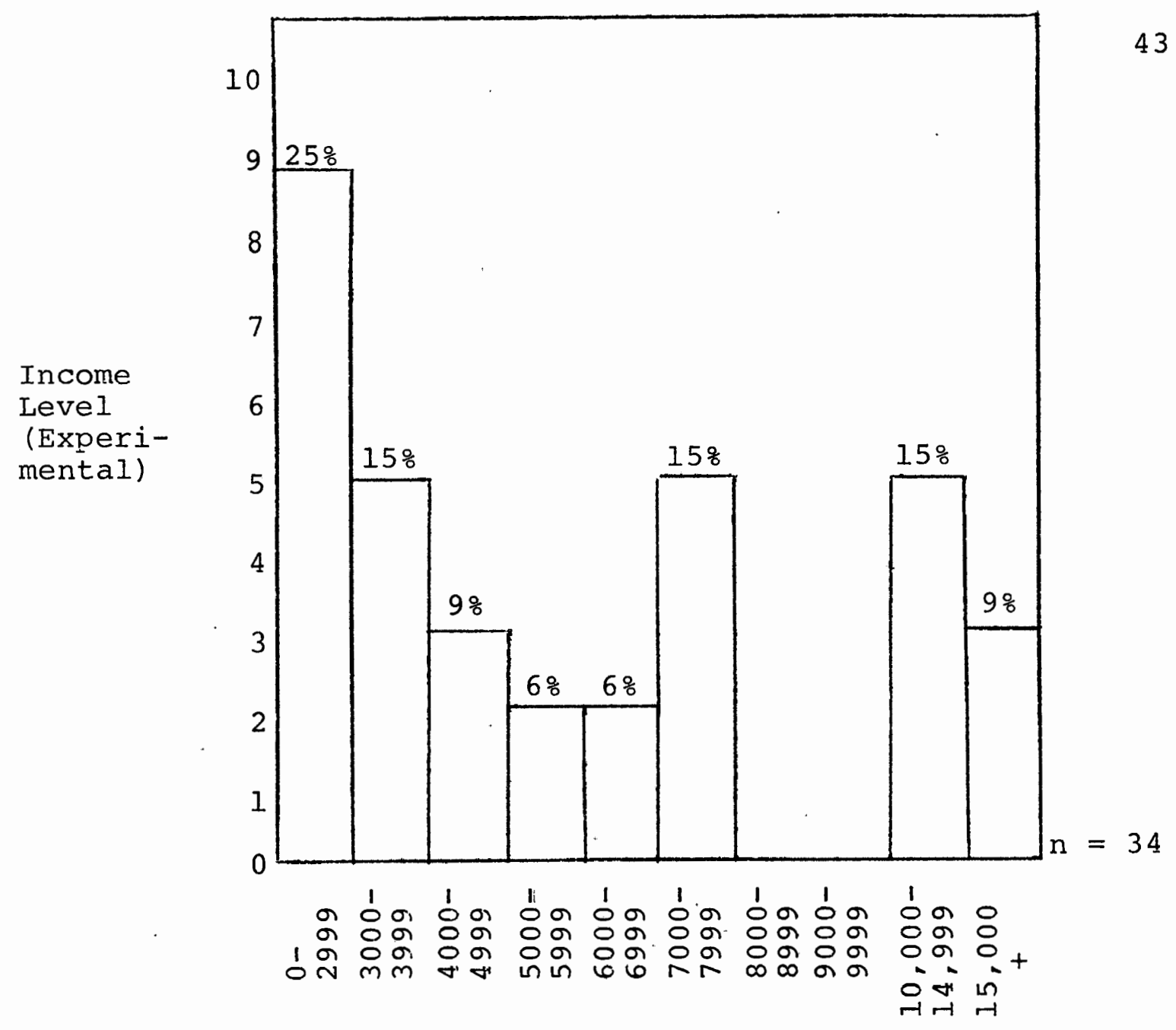

Source

of

Income

\begin{tabular}{|l|c|c|c|c|}
\hline \multirow{2}{*}{} & \multicolumn{2}{|c|}{ Control } & \multicolumn{2}{c|}{ Experimental } \\
\cline { 2 - 5 } & $\mathrm{f}$ & $\circ$ & $\mathrm{f}$ & $\circ$ \\
\hline Self & 33 & 77 & 23 & 74 \\
\hline Other & 10 & 23 & 8 & 26 \\
\hline
\end{tabular}

Currently Employed

\begin{tabular}{|l|c|c|c|c|}
\hline \multirow{2}{*}{} & \multicolumn{2}{|c|}{ Control } & \multicolumn{2}{c|}{ Experimental } \\
\cline { 2 - 5 } & $\mathrm{E}$ & $\%$ & $\mathrm{f}$ & $\%$ \\
\hline Yes & 25 & 57 & 18 & 64 \\
\hline No & 19 & 43 & 10 & 36 \\
\hline
\end{tabular}


Referral

Source

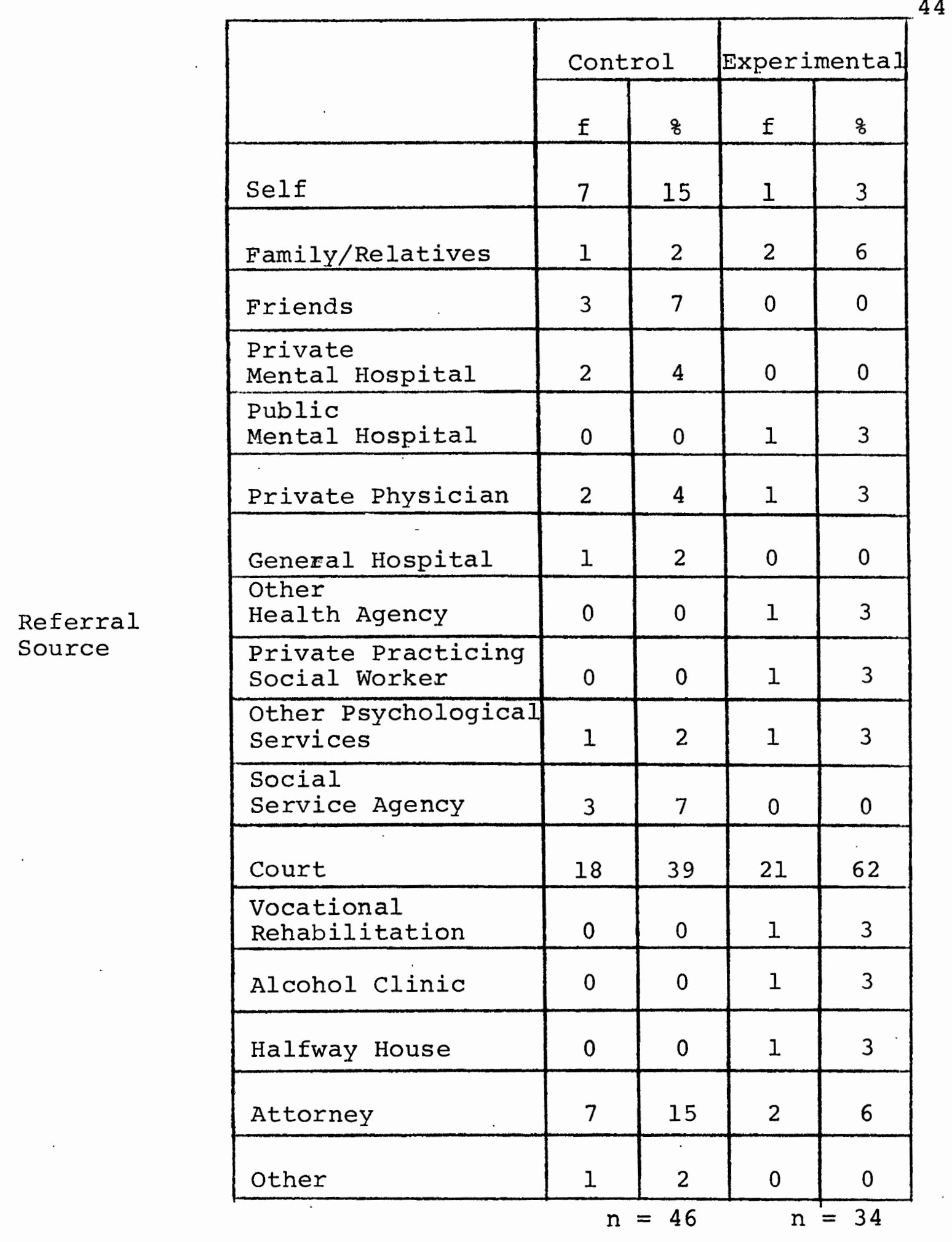

Number of

Arrests for

Driving While Intoxicated (Mean)

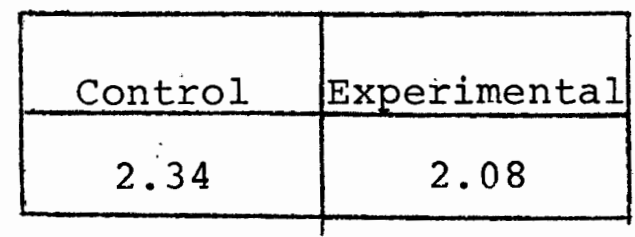




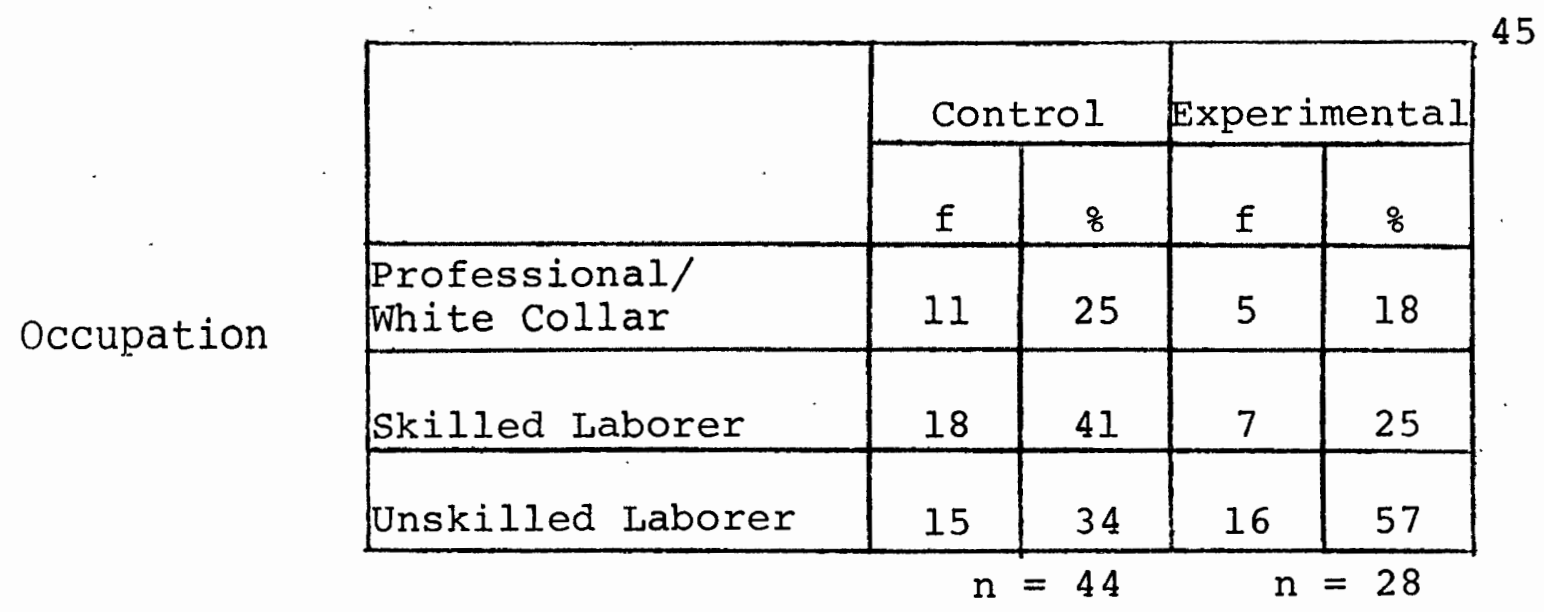

Number of

Dependents (Mean)

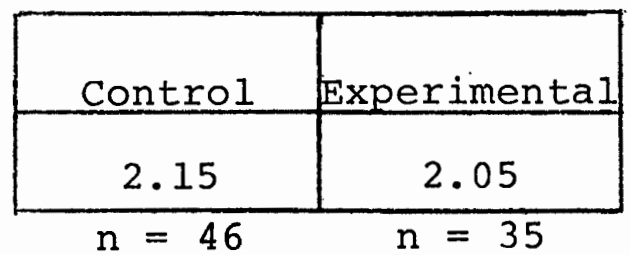

Previous

Treatment

Alcoholic Parent

Phase of Addiction

\begin{tabular}{|l|c|c|c|c|}
\hline \multirow{2}{*}{} & \multicolumn{2}{|c|}{ Control } & \multicolumn{2}{c|}{ Experimenta ] } \\
\cline { 2 - 5 } & $\mathrm{f}$ & 8 & $\mathrm{f}$ & 8 \\
\hline Yes & 22 & 48 & 13 & 37 \\
\hline No & 24 & 52 & 22 & 63 \\
\hline
\end{tabular}

\begin{tabular}{|l|c|c|c|c|}
\hline \multirow{2}{*}{} & \multicolumn{2}{|c|}{ Control } & \multicolumn{2}{c|}{ Experimental } \\
\cline { 2 - 5 } & $\mathrm{f}$ & $\circ$ & $\mathrm{f}$ & $\%$ \\
\hline Yes & 16 & 35 & 10 & 29 \\
\hline No & 30 & 65 & 25 & 71 \\
\hline
\end{tabular}

\begin{tabular}{|c|c|c|c|c|}
\hline & \multicolumn{2}{|c|}{ Control } & \multicolumn{2}{c|}{ Experimenta] } \\
\cline { 2 - 5 } & $\mathrm{f}$ & $\%$ & $\mathrm{f}$ & $\%$ \\
\hline Level 1 & 39 & 85 & 29 & 91 \\
\hline Level 2/3 & 7 & 15 & 3 & 9 \\
\hline
\end{tabular}


Legal

Coercion

\begin{tabular}{|l|c|c|c|c|}
\hline \multirow{2}{*}{} & \multicolumn{2}{|c|}{ Contro1 } & \multicolumn{2}{c|}{ Experimental } \\
\cline { 2 - 5 } & $\mathrm{f}$ & $\circ$ & $\mathrm{f}$ & $\circ$ \\
\hline Yes & 25 & 54 & 26 & 74 \\
\hline No & 21 & 46 & 9 & 26 \\
\hline
\end{tabular}

Schedule of Recent Experience (Mean)

\begin{tabular}{|c|c|}
\hline Control & Experimental \\
\hline 1432.60 & 1533.07 \\
\hline$n=35$ & $n=15$ \\
\hline
\end{tabular}




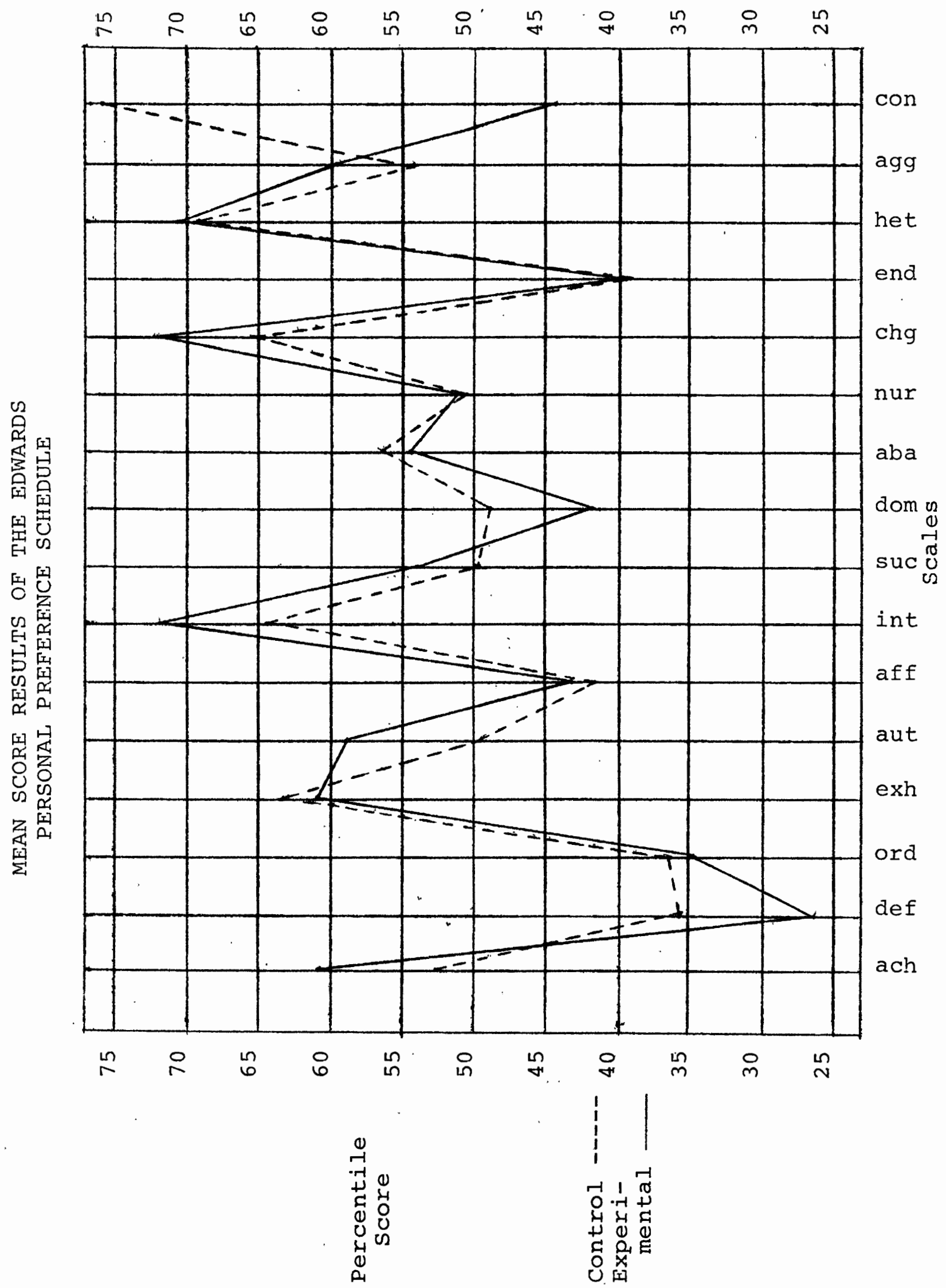


CHAPTER X

\section{DISCUSSION OF RESULTS}

The findings of the present study indicate that persons completing the intake process are distinguishable from noncompleters on a number of demographic and psychological characteristics. Of the twelve variables found to significantly differentiate the two groups, only one (ethnic group) was not found significant in other related studies.* A comparison of the findings of the present study with those of previous related studies is presented in Table III.

Noncompleters of the intake process were found to be younger than completers. This may be due to the greater geographic mobility of younger persons. That is, they are "less likely to have nuclear family and community ties or relatively binding obligations to aged parents" (Baekeland and Lundwall, 1975, p. 763).

Noncompleters tended to be never married, divorced, separated, or widowed. Two possible explanations for this finding are: (1) the noncompleter has poor ability for

* The twelfth variable "consistency on the EPPS," however, was not considered in any of the studies cited. It is discussed here with regard to the possibly related finding of high field dependence among outpatient alcoholism treatment dropouts. 
TABLE III

\section{CHARACTERISTICS OF NONCOMPLETERS: COMPARISON OF PRESENT STUDY WITH PREVIOUS RELATED STUDIES}

\begin{tabular}{|c|c|c|}
\hline Variable & $\begin{array}{l}\text { Results of } \\
\text { Present Study }\end{array}$ & $\begin{array}{l}\text { Results of } \\
\text { Previous studies* }\end{array}$ \\
\hline Age & Younger & $\begin{array}{l}\text { Younger (Inpatient } \\
\text { Alcoholism), (Indi- } \\
\text { vidual Psychotherapy-- } \\
\text { short term) }\end{array}$ \\
\hline \multirow[t]{2}{*}{$\begin{array}{l}\text { Marital } \\
\text { status }\end{array}$} & $\begin{array}{l}\text { Never married, di- } \\
\text { vorced, separated, } \\
\text { or widowed }\end{array}$ & $\begin{array}{l}\text { Single or separated } \\
\text { (Outpatient Alcohol- } \\
\text { ism) }\end{array}$ \\
\hline & 然 & $\begin{array}{l}\text { Socially isolated } \\
\text { (Outpatient Alcohol- } \\
\text { ism), (Inpatient Al- } \\
\text { coholism) }\end{array}$ \\
\hline $\begin{array}{l}\text { Ethnic } \\
\text { group }\end{array}$ & Caucasian & $\begin{array}{l}\text { Black (Intake), (In- } \\
\text { dividual Psychother- } \\
\text { apy) }\end{array}$ \\
\hline $\begin{array}{l}\text { Income } \\
\text { level }\end{array}$ & Lower & $\begin{array}{l}\text { Lower (Outpatient } \\
\text { Alcoholism), (Indi- } \\
\text { vidual Psychotherapy) }\end{array}$ \\
\hline \multirow[t]{2}{*}{ Education } & Less & Slightly more (Intake) \\
\hline & $\begin{array}{l}\text { High school or } \\
\text { earlier dropouts }\end{array}$ & $\begin{array}{l}\text { Less (Outpatient Alco- } \\
\text { holism), (Individual } \\
\text { Psychotherapy) }\end{array}$ \\
\hline Occupation & Lower status & $\begin{array}{l}\text { Lower status (Out- } \\
\text { patient Alcoholism), } \\
\text { (Individual Psycho- } \\
\text { therapy) }\end{array}$ \\
\hline $\begin{array}{l}\text { Phase of } \\
\text { alcohol } \\
\text { addiction }\end{array}$ & More advanced & $\begin{array}{l}\text { More advanced (Out- } \\
\text { patient Alcoholism), } \\
\text { (Inpatient Alcoholism) }\end{array}$ \\
\hline
\end{tabular}

* The setting of the previous studies is enclosed in parentheses. For reference to the specific studies, see Chapter IV. 
TABLE III (cont'd)

$\begin{array}{ll}\text { Variable } & \begin{array}{l}\text { Results of } \\ \text { Present Study }\end{array} \\ \begin{array}{l}\text { Legal } \\ \text { coercion }\end{array} & \text { More often }\end{array}$

Deference

Autonomy

Aggression

Consistency
Lower

Higher

Higher
Results of Previous Studies

More often (Outpatient Alcoholism)

Less often (Outpatient Alcoholism)

Lower (Outpatient Alcoholism)

Higher (Outpatient Alcoholism)

Higher (Inpatient Alcoholism)

[Not studied*]

forming ties with other persons, be it a spouse or intake worker; and (2) the noncompleter, apparently lacking a significant other, has no one close to him interested in his receiving treatment and, therefore, lacks the external motivation (be it of a concern or coercive nature) necessary for completing intake.

Noncompleters were more often Caucasian, a finding inconsistent with other related studies. This, however, may have been due to the sample size of non-whites being too small (seven in the completer group and three in the noncompleter group), and therefore possibly not an accurate representation of the non-white population.

\footnotetext{
* See discussion, p. 55 and 56.
} 
Noncompleters tended to be of lower socioeconomic status (SES), as measured by their lower income level, less education, and lower status occupation. Much has been written about the tendency of lower SES persons to drop out of treatment, and it is very likely that some of these explanations also apply to intake process noncompleters. The following explanations have been extrapolated from the treatment dropout literature: (1) Intake workers are middle class, with middle class values and perceptions and, therefore, "may only very imperfectly understand many facets of the life of the lower class person" (Ibid., p. 764), and thus may be unable to establish the rapport necessary for a working relationship with the client. (2) Lower SES clients tend to be more poorly motivated, less patient, and less discontented and dissatisfied with themselves than middle class clients (Ibid.). (3) Lower SES clients tend to be present-oriented, rather than future-oriented (Ibid.), and thus less likely to be able to withstand a lengthy wait before receiving treatment. (4) Lower SES clients tend to be affected by practical barriers to attending intake sessions, such as lack of transportation, lack of funds for child care, and mobility in residence and employment (Eiduson, 1968, p. 913).

It should be noted that in one pre-treatment study (Brandt, 1963), dropouts were found to have slightly more education than completers. One possible explanation for this inconsistency, is Brandt's having studied a somewhat 
different group of pre-treatment dropouts than those of the present study. That is, Brandt compared "rejectors" with "acceptors" of psychotherapy; rejectors being those persons who failed to appear for treatment following intake, and did not apply for treatment elsewhere within four months. He found that only 37 of 100 persons failing to show for treatment were true rejectors of psychotherapy. In the present study there was no control for the possibility of noncompleters entering treatment elsewhere, and it may be that a significant proportion of them did begin treatment elsewhere, thereby possibly making the composition of Brandt's rejectors and the noncompleters of the present study considerably different.

Another finding concerning education in the present study was the tendency of noncompleters to be high school or earlier dropouts. A rather speculative, but plausible hypothesis to explain this result, is that pre-treatment dropouts have a proclivity for dropping out of things in general.

Noncompleters tended to be in a more advanced phase of alcohol addiction, having more severe symptoms. It has been found that clients, in general, with low symptom levels tend to drop out of treatment, and it "seems that up to a point, anxiety and the need for relief from it may act not only as an incentive to the [client's] entering treatment in the first place but also to his remaining in it" (Baekeland and Lundwal1, 1975, p. 765). However, there 
is a point at which symptom levels become so high that clients come to have very little tolerance of frustration and delay and, therefore, drop out of treatment if not rapidly given some relief from their symptoms (Ibid.). For alcoholics, who generally tend to be impulsive and have little tolerance of delay (Mayer et al., 1965, p. 485), it is not surprising that those with more severe symptoms would be still less tolerant of delay and would drop out of the lengthy intake process.

Noncompleters were more often legally coerced into treatment. This was also found to be true in some outpatient alcoholism treatment dropout studies, though the reverse was found in other studies (Baekeland and Lundwall, 1975; Zax, Marsey, and Biggs, 1961). These discrepancies may be due to the different consequences for the clients' not remaining in treatment. That is, in some studies clients may have been "legally coerced" in name only, and received little, or no, punishment for dropping out of treatment, while in other studies, clients may have been fined, jailed, or lost their drivers licenses. At the Alcohol Treatment and Training Center coerced clients not completing the intake process and treatment program, either enter treatment elsewhere, are fined, or are jailed. Statistics concerning such, however, were not available. It may be that some coerced clients are "shopping" for the easiest way to fulfill their court mandate to participate in 
a treatment program and decide on an easier route after attending one or more intake sessions at the Center.

Noncompleters scored lower on the deference scale of the Edwards Personal Preference Schedule than completers. The following characteristic statements make up the deference scale:

To get suggestions from others, to find out what others think, to follow instructions and do what is expected, to praise others, to tell others that they have done a good job, to accept the leadership of others, to read about great men, to conform to custom and avoid the unconventional, to let others make decisions. (Edwards, 1959, p. 11)

Intake is structured in such a way that the client is placed in a somewhat submissive position to the intake worker (Gallant et al., 1966, p. 351), requiring a certain degree of deference on the part of the client. Lacking in such, he may be unable, or finds it difficult, to interact with the intake worker appropriately and, therefore, is likely to drop out.

Noncompleters were found to score higher on the autonomy scale. Statements on the EPPS characterizing this trait are:

To be able to come and go as desired, to say what one thinks about things, to be independent of others in making decisions, to feel free to do what one wants, to do things that are unconventional, to avoid situations where one is expected to conform, to do things without regard to what others may think, to criticize those in positions of authority, to avoid responsibilities and obligations. (Ibid.)

A high level of autonomy, as used by Edwards, is not compatible with regular attendance at a rather highly 
structured intake process and, therefore, is expected for noncompleters.

Noncompleters also had higher scores on the aggression scale. Statements relating to this trait are:

To attack contrary points of view, to tell others what one thinks about them, to criticize others publicly, to make fun of others, to tell others off when disagreeing with them, to get revenge for insults, to become angry, to blame others when things go wrong, to read newspaper accounts of violence. (Ibid.)

Again, a high level of this trait is expected for intake process noncompleters. It is also possible that the overtly aggressive client may antagonize the intake worker, who may in turn, consciously or unconsciously, push the applicant out of the intake process.

The above three characteristics (low deference, high autonomy, and aggression), considered together make up the trait "counterdependence," which refers to "those who are resistant to proffered help, insist on their ability to do things for themselves, feel that they do not need anything, and do not believe in the utility of trusting others" (Baekeland and Lundwall, 1975, p. 750). Counterdependence has been found to be related to dropping out of outpatient alcoholism treatment, and it is therefore not surprising that it would also characterize outpatient alcoholic intake process noncompleters.

Lastly, noncompleters were found to score lower on consistency on the EPPS, which means that they less often gave identical responses when asked twice to choose between 
the same pair of statements as to which was more characteristic of themselves. This variable was used by Edwards (1959) only to determine the validity of the test score, and was not considered a personality trait in itself. It is possible, however, that a low consistency score has'some relation to a poorly-defined self-concept, as the subject may be uncertain, in many cases, which trait is more characteristic of himself than another. Such a self-concept is an aspect of "field dependence," which "refers to a cognitive style associated with a poorly differentiated self-concept and reliance on primitive defenses such as denial and repression" (Baekeland and Lundwall, 1975, p. 751). High field dependence was found to be related to dropping out of treatment in outpatient alcoholịsm clinics and, therefore, would not be an unexpected finding for intake process noncompleters of an outpatient alcoholism treatment clinic.

In summary, clients not completing the intake process at the Alcohol Treatment and Training Center differ from completers in the following ways: they are younger, more often never married, divorced, separated or widowed, and more often Caucasian. They have less income and education, and have lower status occupations. They are in a more advanced phase of alcohol addiction, having more severe symptoms, and are more often legally coerced into treatment. They possess less deference, though more autonomy and aggression, indicating a higher level of counterdependence, 
and are less consistent in their answers on the EPPS, possibly indicating greater field dependence. 


\section{CONCLUSION: RECOMMENDATIONS FOR} REDUCING ATTRITION

On the bases of the results of this study and previous studies it appears that there are three changes which could be made in the present intake system at the Alcohol Treatment and Training Center to better accommodate those clients with high-risk dropout characteristics.

Panepinto and Higgins (1969) found that they were able to reduce their first-month dropout rates from $51 \%$ to $28 \%$, in an outpatient alcoholism treatment clinic, by simply sending the clients letters, whenever they missed a treatment session, offering them another appointment with their therapist for the following week. They attribute this response to the letter's showing staff interest in the client. This explanation is in line with the earlier discussion of outpatient alcoholism treatment dropouts' tendency to be single or separated, and socially isolated in general. It is likely that they have no, or few, significant others to motivate them for treatment, and the letters may to some extent replace the missing interest or concern of a significant other, thereby providing them with the external motivation necessary to continue treatment. 
It seems reasonable to assume that sending such letters to intake process noncompleters, who are also apparently lacking a significant other*, would similarly provide them with the necessary external motivation to complete the intake process and enter treatment. Our first recommendation, therefore, is to send reappointment letters to clients as soon as they miss a session.

In the previous chapter it was pointed out that intake process noncompleters are less patient, having little tolerance of frustration or delay, and might be looking for the easiest way of fulfilling a court mandate for treatment. A shorter intake process wherein clients could begin treatment sooner would seem to better accommodate these clients, and this, then, is our second recommendation. One way of shortening the intake process would be to have the intervals between sessions moved from a week long to every other day, or perhaps, to daily sessions. There is a risk that doing such would remove one of the possible functions of the extended intake process, i.e., screening out persons not sufficiently motivated for treatment, and thereby increase the attrition rate for treatment. However, there is no empirical evidence. to the knowledge of these authors indicating that an extended intake process actually serves as such a screening process, and it, therefore, seems a reasonable risk to take.

\footnotetext{
${ }^{\star}$ See discussion, p. 48 and 50.
} 
The final recommendation relates to the probable lack of rapport between the lower SES clients and the middle class intake workers. A possible solution to this problem would be to have lower SES intake workers who could better relate to these clients. Since volunteers are utilized to a large extent at the center, it would seem relatively easy to actively recruit lower SES persons to serve as volunteer intake workers.

If the Center does not wish to make these changes, or is unable to, it would still be possible to accommodate the probable dropouts by the intake workers' familiarizing themselves with the dropout characteristics and then making a formal referral to another clinic which can better serve them.

On the other hand, if the three recommendations are acted upon, it is the expectation of these authors that the rate of attrition from the intake process at the Alcohol Treatment and Training Center will be significantly reduced. It is hoped that a future study testing this hypothesis will be conducted. 


\section{SOURCES CONSULTED}

Armor, D.J., Polich, J.M., and Stambul, H.B. Alcoholism and Treatment. Santa Monica: The Rand Corporation, 1976.

Baekeland, F., and Lundwa11, L. "Dropping Out of Treatment: A Critical Review." Psychological Bulletin 82 (5): 738-83, 1975 .

, Lundwall, L., and Shanahan, T.J. "Correlates of Patient Attrition in the Outpatient Treatment of Alcoholism." Journal of Nervous and Mental Disease $157(2)$ : 99-107, 1973.

Brandt, L.W. "Studies of 'Dropout' Patients in Psychotherapy: A Review of Findings." Psychotherapy: Theory, Research and Practice 2 (1): 6-12, 1965.

"Rejection of Psychotherapy?: The Discovery of Unexpected Numbers of Pseudorejectors." Archives of General Psychiatry 10: 310-13, 1964.

- "Psycholinguistic Analysis of Statements of Problems from Applicants for Psychotherapy -- A Comparison of a Group who Rejected and a Group who Accepted Treatment at Three Mental Health Clinics." Ph.D. dissertation, New York University, 1963.

Butler, N. "Problem Drinking Drivers." Alcohol Safety Action Project, Oregon Mental Health Division, 1974.

Cahalan, D. Problem Drinkers. San Francisco: Jossey-Bass, 1970.

, Cisin, I.H., and Crossley, H.M. "American Drinking Practices: A National Study of Drinking Practices and Attitudes." Monograph No. 6. New Brunswick, NJ: Rutgers Center of Alcohol Studies, 1969.
' and Room, R. "Problem Drinking Among American Men." Monograph No. 7. New Brunswich, NJ: Rutgers Center of Alcohol Studies, 1974.

Cummings, R.E. "A Study of Characteristics of Patients who Fail to Complete a VA Alcoholic Treatment Program." Rehabilitation Literature 36 (5): 139-41, 1975. 
Davies, K.M. "The Influence of Alcohol on Mortality." Proceedings, Home Office Life Underwriters Association. 46 : $159-77,1965$.

Dolan, L.P. "An Intake Group in the Alcoholism Outpatient Clinic." Journal of Studies on Alcohol 36 (7) : 99699,1975 .

Edwards, A.L. Edwards Personal Preference Schedule Manual. New York: The Psychological Corporation, 1959 .

Eiduson, B.T. "Retreat from Help." American Journal of Orthopsychiatry 38 (5): 910-21, 1968 .

Efron, V., Keller, M., and Gurioli, C. "Statistics on Consumption of Alcohol and on Alcoholism." New Brunswick, NJ: Rutgers Center of Alcohol Studies, 1974.

Fiester, A.R., Mahrer, A.R., Giambra, L.M., and Ormiston, D.W. "Shaping a Clinic Population: The Dropout Problem Reconsidered." Community Mental Health Journal 10 (2) : $173-79,1974$.

Fitzgerald, B.J., Pasewark, R.A., and Tanner, C.E. "Use of the Edwards Personal Preference Schedule with Hospitalized Alcoholics." Journal of Clinical Psychology 23 (2): 194-5, 1967.

Gallant, D.M., Bishop, M.P. Stoy, B., Faulkner, M.A., and Paternostro, I. "The Value of a 'First Contact' Group Intake Session in an Alcoholism Outpatient Clinic: Statistical Confirmation." Psychosomatics, 7 (NovemberDecember): $349-52,1966$.

Garcea, R.A. and Irwin, O. "A Family Agency Deals with the Problem of Dropouts." Social Casework 43 (2): 71-75, 1962.

Gibby, R.G., Stotsky, B.A., Hiler, E.W., and Miller, D.R. "Validation of Rorschach Criteria for Predicting Duration of Therapy." Journal of Consulting Psychology 18 (3) : 185-91, 1954 .

, Stotsky, B.A., Miller, D.R., and Hiler, E.W. "Prediction of Duration of Therapy from the Rorschach Test." Journal of Consulting Psychology 17 (5): 348$54,1953$.

Goldfried, M.R. "Prediction of Improvement in an Alcoholism Outpatient Clinic." Quarterly Journal of Studies on Alcohol 30: 129-39, 1969 . 
Goucher, E.L. "Why Do Veterans Break Treatment?" Masters thesis, Simmons College, 1949.

Gould, R.I., Paulson, I., and Daniels-Epps, L. "Patients who Flirt with Treatment: The Silent Population." American Journal of Psychiatry 127 (4): 524-29, 1970.

Gross, W.F., and Nerviano, V.J. "The Prediction of Dropouts from an Inpatient Alcoholism Program by Objective Personality Inventories." Quarterly Journal of Studies on Alcohol 34: 514-15, 1973 .

Hague, W.H., Donovan, D.M., and O'Leary, M.R. "Personality Characteristics Related to Treatment Decisions among Inpatient Alcoholics: A Non-Relationship." Journal of Clinical Psychology 32 (2): 476-79, 1976 .

Harris, L., and Associates, Inc. "Public Awareness of the National Institute on Alcohol Abuse and Alcoholism Advertising Campaign and Public Attitudes Toward Drinking and Alcohol Abuse." Reports prepared for the National Institute on Alcohol Abuse and Alcoholism, 1972-1974, 1974 .

Heinemann, D., Moore, B., and Gurel, M. "Completion or Termination of Alcoholism Treatment: Toward a Development of a Predictive Index:" Psychological Reports 38: $1340-42,1976$.

Holmes, T.H. "Life Style, Life Event and Disease." Closing address at a meeting on cooperative research among veterans administrations hospitals. University of Washington School of Medicine, April 6, 1968.

Scale:" and Rahe, R.H. "The Social Readjustment Rating
1967.

, and Rahe, R.H. Booklet for Schedule of Recent Experience (SRE). Seattle: University of Washington School of Medicine, Department of Psychiatry, 1967.

Horenstein, D. "Correlates of Initial Client Disturbance: Expectations for Therapy, Dropout, Resistance, and Demographic Description." Journal of Clinical Psychology $31(4): 709-15,1975$.

Imber, S.D., Nash, E.H., and Stone, A.R. "Social Class and Duration of Psychotherapy." Journal of Clinical Psychology 11 (3): 281-84, 1955 . 
Kalb, M. "Social Class, Length of Treatment Contacts and Outpatient Treatment of Alcoholism." British Journal of Addiction 70: 253-62, 1974 .

Keller, M., ed. U.S. Dept. of Health, Education and Welfare: National Institute on Alcohol Abuse and Alcoholism. Second Special Report to the U.S. Congress on Alcohol and Health, from the Secretary of Health, Education, and Welfare. (DHEW Publication No. HSM-72-9099.) Washington, D.C.: U.S: Government Printing Office, 1974.

Kline, J., and King, M. "Treatment Dropouts from a Community Mental Health Center." Community Mental Health Journal 9 (4): 354-60, 1973.

Krasnoff, A. "Differences Between Alcoholics who Complete or Withdraw from Treatment." Journal of studies on Alcohol 37 (11): 1666-71, $197 \overline{6 .}$

Krause, M.S. "Predicting Client Discontinuance at Intake." Social Casework 43 (6): 308-12, 1962 .

"Comparative Effects on Continuance of Four Experimental Intake Procedures." Social Casework 47 (8): 515-19, 1966 .

Levinger, G. "Continuance in Casework and Other Helping Relationships: A Review of Current Research." Social Work 5 (3): 40-5I, 1960.

Loeb, A., and Scoles, P. "Reactivating Dropouts from a Psychiatric Rehabilitation Program." Social Work 13 (3) : $48-54,1968$.

Lorber, J. and Satow, R. "Dropout Rates in Mental Health Centers." Social Work 20 (4): 308-12, 1975.

Lorr, M., Katz, M.M., and Rubinstein, E.A. "The Prediction of Length of Stay in Psychotherapy." Journal of Consulting Psychology 22 (5): 321-27, 1958.

Mayer, J., Needham, M.A., Myerson, D.J. "Contact and Initial Attendance at an Alcoholism Clinic." Quarterly Journal of Studies on Alcohol 20: 480-85, 1965 .

Meyer, R.G. "The Dropout as a Function of Psychotherapeutic Strategies: A Case Study." Psychotherapy: Theory, Research and Practice 6 (1): $46-48,1969$. 
Mules, J.E., Hague, W.H., Dudley, D.L. "Life Change, Its Perception and Alcohol Addiction." Journal of Studies on Alcohol 38 (3): 487-93, 1977 .

Nielsen, R.C. "A Study of Premature Termination of Outpatient Psychotherapy in the Community Mental Health Center." (Ed.D dissertation, University of Northern Colorado, 1973.) Dissertation Abstracts International 34: $2314-B, 1973$.

Noonan, J.R. "A Followup of Pretherapy Dropouts." Journal of Community Psychology 1 (1): 43-44, 1973.

Office of County Management, Multnomah County. "Catalog of County Programs (Program Objectives Productivity System)." Portland, OR, 1976.

Panepinto, W.C., and Higgins, M.J. "Keeping Alcoholics in Treatment: Effective Follow-through Procedures.". Quarterly Journal of Studies on Alcohol 30: 414-19, 1969.

Pell, S., and D'Alonzo, C.A. "A Five-Year Morality Study of Alcoholics." Journal of Occupational Medicine 15: $120-25,1973$.

Perlman, H.H. "Intake and Some Role Considerations." Social Casework 41 (4): 171-77, 1960 .

Pfouts, J.H., Wallach, M.S., and Jenkins, J.W. "An Outcome Study of Referrals to a Psychiatric Clinic." Social Work 8 (3): 79-86, 1963.

Pryer, M.W., and Distefano, M.K. "Further Evaluation of the EPPS with Hospitalized Alcoholics." Journal of Clinical Psychology 26 (2): 205, 1970 .

Raynes, A.E., and Warren, G. "Some Distinguishing Features of Patients Failing to Attend a Psychiatric clinic after Referral." American Journal of Orthopsychiatry

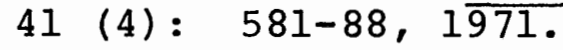

Rogers, L.S. "Drop-out Rates and Results of Psychotherapy in Government Aided Mental Hygiene Clinics." Journal of Clinical Psychology 16 (1): 68-92, 1960.

Rooney, H.L., and Miller, A.D. "A Mental Health Clinic Intake-Policy Project." Mental Hygiene 39 (3): 391405,1955 . 
Rorabaugh, W.J. "Estimated U.S. Alcoholic Beverage Consumption, 1790-1860." Journal of Studies on Alcohol 37 (3): $357-64,1976$.

Rosenberg, C.M., and Liftik, J. "Use of Coercion in Outpatient Treatment of Alcoholism." Journal of Studies on Alcohol 37 (1): 58-65, 1976 .

Rubinstein, E.A., and Lorr, M. "A Comparison of Terminators and Remainers in Outpatient Psychotherapy." Journal of Clinical Psychology 12 (4): 345-49, 1956.

Schmidt, W., and de Lint, J. "Causes of Death of Alcoholics." Quarterly Journal of Studies on Alcohol 33: $171-85, \frac{1972 \text {. }}{1972}$

Schmidt, W., Smart, R.G., and Moss, M.K. Social Class and the Treatment of Alcoholism. Toronto: University of Toronto Press, 1968.

Scott, E.M. Struggles in an Alcoholic Family. Springfield, IL: Charles C. Thomas, Inc., 1970.

, Keener, J., and Manaugh, T.S. "Treatment of Alcoholism in an Out-patient Clinic in Oregon." International Journal of Offender Therapy and Comparative i. $\quad$ Criminology $21(2): \frac{141-52,}{1977 .}$

Seeman., M.V. "Patients. who Abandon Psychotherapy: Why and When." Archives of General Psychiatry 30: 486-91, 1974 .

Siporin, M. Introduction to Social Work Practice. New York: Macmillan Publishing Co., Inc. , $197 \overline{5}$.

Tarleton, G.H., and Tarnower, S.M. "The Use of Letters as Part of the Psychotherapeutic Relationship." Quarterly Journal of Studies on Alcohol 21: 82-89, 1960 .

Taulbee, E.S. "Relationship Between Certain Personality Variables and Continuation in Psychotherapy." Journal of Consulting Psychology 22 (2): 83-89, 1958.

Wanberg, K.W., and Jones, E. "Initial Contact and Admission of Persons Requesting Treatment for Alcohol Problems." British Journal of Addiction 68: 281-85, 1973.

Yalom, I.D. "A Study of Group Therapy Dropouts." Archives of General Psychiatry 14: 393-414, 1966. 
Zax, M., Marsey, R., and Biggs, C.F. "Demographic Characteristics of Alcoholic Outpatients and the Tendency to Remain in Treatment." Quarterly Journal of Studies on Alcohol 22 (1): 98-105, 1961 . 